carlos alberto viana costa $1^{-12}$

\title{
CONTRIBUIÇÃO AO ESTUDO DO SISTEMA DE INFORMAÇÃO, DECISÃO E CONTROLE DAS ZOONOSES NO BRASIL
}

\author{
Dissertação apresentada à Faculdade de Saúdo \\ Pública da Universidade de São Paulo para \\ obtenção do título de Mestre em Saúde Pública
}

\section{SÃO PAULO}

1977

BIBLIOTECA

FACULDADE DE SALUE PÜBLICA

UNVVERSIDADE DE SÁO PAULO

$S P-8$ 
A memōria de minha mãe que, pelo seu exemplo de vida crista, me fez conhecer o AMOR e O DEVER. 
o autor agradece,

a todos que colaboraram na realização deste trabalho.

Especial menção faz-se ao Prof. Dr. Gil Vianna Paim. pela sua competente orien tação e amizade. 
INDICE

Pág.

RESUMO

1. INTRODUÇÃO $\ldots \ldots \ldots \ldots \ldots \ldots \ldots \ldots \ldots \ldots$

1.1. Estatistica Vital $\ldots \ldots \ldots \ldots \ldots \ldots \quad 10$

1.2. Epidemiologia .............. 11

1.3. Vigilância Epidemiológica ...... 15

2. SISTEMAS DE INFORMAÇÕES DE SAUDE $\ldots \ldots \ldots 19$

2.1. Sub-Sistema de Informação ....... 21

2.2. Sub-Sistema de Decisão $\ldots \ldots \ldots \ldots .32$

2.3. Sub-Sistema de Controle ........ 35

3. CONSIDERAÇÕES SOBRE A ATUAL SITUAÇÃO DOS SISTEMAS DE INFORMAÇÕES DE SAUDE $\ldots \ldots \cdot 37$

3.1. Nas Américas $\ldots \ldots \ldots \ldots \ldots \ldots \ldots .38$

3.2. No Brasil $\ldots \ldots \ldots \ldots \ldots \ldots \ldots \ldots, 45$

4. PROPOSIÇÕES PARA MUDANÇA $\ldots \ldots \ldots \ldots \ldots 67$

4.1. Proposição A .............. 69

4.2. Proposição B $\ldots \ldots \ldots \ldots \ldots \ldots \ldots \ldots \quad 70$

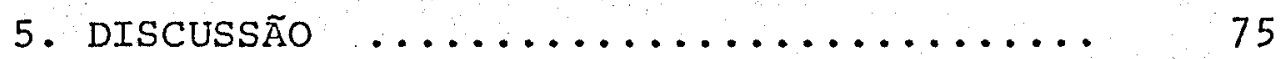

6. CONCLUSÕES $\ldots \ldots \ldots \ldots \ldots \ldots \ldots \ldots \ldots$

ABSTRACTS $\ldots \ldots \ldots \ldots \ldots \ldots \ldots \ldots \ldots \ldots \ldots$

REFERENCIAS BIBLIOGRAFICAS $\ldots \ldots \ldots \ldots .85$

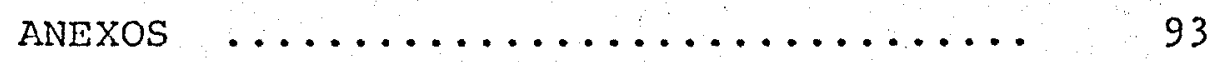




\section{LISTA DE FIGURAS E ANEXOS}

FIGURA 1 - Sistema de informação, decisão e controle das doenças transmissiveis e zo onoses.

FIguRA 2 - Fluxograma do Programa Nacional de Pro filaxia da Raiva.

FIguRA 3 - Organograma da Divisão Centro de Controle de Zoonoses, da Prefeitura Muni cipal de são Paulo.

ANEXO 1 - Ficha individual de tratamento antirábico humano.

ANEXO 11 - Ficha de informação epidemiológica de casos de Raiva humana.

ANEXO 111 - Ficha de informação epidemiológica de complicações neuroparaliticas humanas associadas com a vacinação anti-rábi. ca.

ANEXO IV - Ficha comprovante de vacinação antirábica canina.

ANEXO $V$ - Ficha residencial para inquérito da po pulação canina.

ANEXO VI - Certificado de Inspeção Sanitäria Ani mal.

ANEXO VII - Ficha nosogräfica.

ANEXO VIII - Boletim informativo de occirrência de Febre aftosa.

ANEXO IX - Boletim informativo de encerramentode surto de Febre aftosa.

ANEXO $X$ - Ocorrência de Raiva canina - Notificação.

ANEXO XI - Ficha de entrada do animal. 


\section{RESUMO}

Após conceituar estatistica, bioestatistica, epidemiologia, vigiláncia epidemiológica e sistema, o autor analisa o sistema de informação, decisão e controle das doenças transmissiveis e zo onoses, aplicado às estatisticas de saúde em zoono ses no Brasil.

a autor conclui que as estatisticas de sa úde em zoonoses no Brasil deixam muito a desejar. à semelhança da maioria dos países latino-americanos. O administrador sanitário não dispãe de esta tísticas confiáveis, em qualidade ou quantidade su ficientes, para tomar decisões rápidas, eficientes e realistas.

Propōe a criação de uma Unidade de Saúde Püblica Veterinária, como parte integrante do Ministério da saúde. Propõe também a criação de um Centro Nacional de Controle de Zoonoses e de Centros Estaduais de Controle de Zoonoses com ampla participação dos órgãos públicos e iniciativa privada. Todos com a finalidade primordial de promover melhor integração dos Setores de Saúde Humana e Saúde Animal e de dinamizar o sistema de informa ção, decisão e controle das zoonoses no Brasil. 
1. INTRODUÇĀO 
1. INTRODUÇAO

o presente trabalho pretende verificar e analisar as estatisticas de saúde dé zoonoses no Brasil, tomando como modelo o sistema de informação, decisão e controle das doenças transmissiveis e zoonoses, proposto pela Organização Panamericana da Saúde - OPAS (1974). Foram utilizadas pesquisas bibliogräficas, consultas por cartas, entrevis tas e a própria experiência do autor nesse campo. Foram, também, visitadas várias instituições dos Se tores de Saúde Humana e de Saúde Animal, para melhor conhecimento e complementação. Através da análise da situação do sistema de informação, decisão e controle das zoonoses no Brasil, são propostas mudanças que venham produzir melhorias em todo o sistema.

Zoonoses, são doenças ou infecções que se transmitem naturalmente entre os animais vertebrados e o homem, e vice-versa (OMS, 1967). 


\subsection{ESTATISTICA VITAL}

o desenvolvimento de uma comunidade, de uma região ou de um país, implica em uma sērie de fenômenos entre si, que se ajustam e se completam, para um melhor aproveitamento dos recursos existen tes. Ao método de estudo aplicado às vārias ciências para organizar numericamente esses fatos ou fe nômenos, dá-se o nome de Estatística (SOUNIS, 1971). A Estatística serve para estimular o raciocínio e organizar a experiência diāria de uma maneira coerente. (KLOETZEL, 1973). Na ārea de ciēncias bioló gicas, a aplicação da Estatistica vem conferindoum maior rigor científico às investigações, a tal pon to que surgiu uma nova denominação, a Bioestatisti ca, ou Estatistica Vital. Hoje, os trabalhos cien tíficos e de pesquisa não podem prescindix de anālise pelo método estatístico para concluir, em bases matemāticas, da significância ou não dos achados, ou pela existência ou não da correlação entre as variāveis ou, ainda, de um modo geral, na inter pretação dos resultados (SOUNIS, 1971).

Fatos vitais, segundo as Nações unidas (1953), citados por BERQUo et al. (1972), são os se 
guintes: nascimentos vivos, óbitos, óbitos fetais, casamentos, divörcios, adoções, legitimaçōes, reco nhecimentos, anulações e separações. Todavia, estes conceitos, hoje em dia, já ultrapassaram emmui to a especialidade médica, indo para o domínio das ciências biológicas em geral. Em međicina veterinária aceita-se como fatos vitais, além dos relacionados propriamente à vida animal; como nascimen to e morte, as variáveis como sexo, idade, número de indivíduos, movimentação (trânsito), comerciali zação, etc. (DEAK, 1973).

A Bioestatística, ou Estatística Vital, se ocupa dos dados ou fenômenos vitalis coletivos.

Para o sanitarista, o conhecimento das es tatísticas de saúde, como os coeficientes de morta lidade, morbidade, letalidade, dose letal 50\% e tan tos outros, dá oportunidade de melhor analisar os problemas coletivos, possibilitando-Ihe melhores con dições para decidir.

\subsection{EPIDEMIOLOGIA}

o conceito de Epidemiologia tem evoluido através dos tempos e, provavelmente, sofrerá ainda

\section{BIBLIOTECA}


mudanças conceituais e metodológicas no futuro. ELKIN (1961), discorrendo sobre a história da Epidemiologia, afirma que se originou da necessidade de se combater as doenças infecciosas muito antes que a natureza dessas doenças fosse pensada, muito antes que sua patogenicidade fosse investigada e antes que os fatores que governam sua ocorrênciae di fusão fossem conhecidos. Este autor demonstra que desde a Antiguidade, ou mesmo antes, doenças infec ciosas existiam, causando calamidades. Os antigos envidaram esforços para debelä-las. Registros, co mo os papiros egípcios, a Bíblia, as Leis de Maru na India, a literatura chinesa, os trabalhos de $\mathrm{H} \underline{\mathbf{i}}$ pöcrates, a "Ilíada" e a "Odisséia" de Homero, com provam esta afirmativa. O estudo da Epidemiologia estava vinculado ao aparecimento das epidemias, sen do reconhecida como a ciência das epidemias (MACMAHON et al.; 1965).

Todavia, já em 1927, ZABOLOTNY1, citado por ELKIN (1961), dava a seguinte definição: Epidemiologia, ou ciência das epidemias, está relacio nada ao estudo da origem e desenvolvimento das epi demias. Está devotada a descobrir as causas que fa vorecem sua propagação e a elaboração de medidas de controle baseadas em dados científicos e práticos. 
O objetivo da Epidemiologia è descobrir e determinar as leis e fatores que favorecem a ori gem, propagação e declínio das epidemias, para a completa eliminação das doenças infecciosas (ELKIN, 1961).

Partindo dos critérios de prevenção, con trole e erradicação, SCHWABE (1968) empresta à sua definição sobre Epidemiologia, um cunho eminentemente ecológico. Afirma ser a Epidemiologia o estudo das correlações entre os grupos da população e o seu meio ambiente que se traduzem em enfermida de. Em Epidemiologia está implícito o estudo ecológico de toda uma população. Fica estabelecida en tão, a trilogia hospedeiro-agente etiológico-meio ambiente.

A Epidemiologia vem ampliando seus métodos e campos de atuação, lançando mão de muitas ou tras disciplinas para o cumprimento de seus objeti vos. Hoje está plenamente aceita a aplicação do termo Epidemiologia não somente para doenças infec ciosas, como tambēm para doenças não infecciosas, crônicas e degenerativas, como exemplo, as doenças cardiovasculares, O câncer (SCHWABE, 1968; LAUREN TI, 1975). 
A Epidemiologia estuda as causas e métodos de prevenção para qualquer fenōmeno que interfira na saúde da população, como exemplo, os acidentes de trânsito (LAURENTI et al., 1972).

Até há pouco tempo, era comum së usar o termo Epidemiologia somente para o relacionado com a população humana, e epizootiologia para o relacio nado com a população animal. porēm, com a aceitação do princípio ecológico de que o homem não está sō, mas inserido em um ecossistema, do qual sua so brevivência depende do equilíbrio que houver entre a sua espécje e as demais espécies animais e vegetais que fazem parte integrante do mesmo, o campo de ação da Epidemiologia extravasou os limites da espécie humana, caindo no domínio de outras disciplinas relacionadas ao meio, como a Agricultura e a Veterināria. Desta forma, não hā necessidade de se fazer distinção entre uma terminologia e outra, podendo-se usar o termo Epidemiologia para outras espécies animais que não o homem, conforme atesta a literatura cientifica atual (SCHWABE, 1968; FOS SAERT et al., 1974; OPAS, 1974). 


\subsection{VIGILÂNCIA EPIDEMIOLOGICA}

"A saũae pública é um processo em constante mudança que incorpora novos conceitọs e méto dos, cada vez mais científicos, apoiando-se no método epidemiológico. Deste modo, com o objetivo de assinalar a necessidade de agilizar a utilização da epidemiologia, se antepôs a palavra "vigilância" pa ra dar a entender que é indispensável um melhor e maior conhecimento da enfermidade e sua interação com o hospedeiro e ambos com o ambiente em que existem" (BURQUETE OSORI0, 1972). "A vigilância epidemiológica é, portanto, o estudo integral da en fermidade, compreendendo a dinâmica do processo móx bido, o substrato ecológico, o agente causal, o hos pedeiro e os reservatórios, bem como os mecanismos responsāveis pela ocorrência dos casos e sua disse minação, entre os quais estã a situação imunolōgica da população" (BURQuete osorio, 1972).

o conceito de vigilância epidemiológica, aplicado ao estudo das doenças em grupos de popula ção, e não em indivíduos, adveio da necessidade de se conhecer com detalhes os focos residuais e os 
fatores que condicionavam a persistência de algumas doenças - malāria, bouba, variola, febre amare la urbana - já sob controle, com possibilidade de progredir no caminho da erradicação. Desta forma, - termo vigilância de uma doença se aplicou ao conjunto de atividades e conhecimentos necessārios pa ra guiar os programas de controle das doenças trans missiveis (FOSSAERT et al., 1974).

o termo vigilância individual, ou simples mente vigilância, se usa para designar, em quarentena, a observação rigorosa, médica ou de outra na tureza, dos contatos, a fim de facilitar o pronto diagnóstico da infecção ou doença, porém sem thes restringir a liberdade (OPAS, 1973). O termo vigi lância epidemiológica surgiu inicialmente em 1955, quando o Centro de Doenças Transmissiveis o usou pela primeira vez. Em 1968, foi consagrado mundialmente pela comunidade cientifica, quando da 21 . Assembléia Mundial de Saũde (FOSSAERT et al., 1974). Em 1962, LANGMUIR, citado por FOSSAERT et al.(1974), definiu a vigilância epidemiológica como sendo a observação ativa e permanente da distribuição e ten dências da incidência mediante a coleta sistemática, a consolidação e a avaliação de informes de mor bidade e mortalidade, assim como de outros dados re 
levantes. A interpretação dos dados bāsicos e sua competente divulgação a todos que os geraram e dos que necesșitam conhecê-los, está intrínseca nessa definição. RASKA (1966), considera a vigilância e pidemiológica um estado de alerta permanente, um processo dinâmico, capaz de registrar, rastrear e avaliar não só a ocorrência da doença, mas também sua propagação na população humana e nos animais quando estes intervêm no ciclo da infecção. Amplí ando o conceito de LANGMUIR (1962), FOSSAERT etal. (1974) definem a vigilância epidemiológica como o conjunto de atividades que permitem reunir a infor mação indispensável para conhecer, em todo momento, a conduta ou história natural da doença, detectar ou prever qualquer mudança que possa ocorrer pox alterações nos fatores condicionantes, com o fim de recomendar oportunamente, sobre bases firmes, as medidas indicadas, eficientes, que levem à prevenção e ao controle da doença. Nesta extensa, porém pródiga definição, podemos identificar muitas das funções e propósitos da vigilância epidemiológica.

Concluindo e reunindo a maioria dos conceitos aqui apresentados, a OPAS (1974) define a vigilância epidemiológica como um sistema dinâmico que se utiliza para observar de perto e em forma 
permanente, todos os fatores que condicionam o fenômeno saúde-doença, mediante a identificação dos fatos, a coleta, análise e interpretação sistemātị ca dos dados e a distribuição dos resultados e das recomendações necessárias. 
2. SISTEMAS DE. INFORMAÇOES DE SAODE 
2. SISTEMA DE INFORNAÇOES DE SAODE

CARVALHO (1976) define um sistema como um conjunto de partes interdependentes visando alcaņ̧ar um objetivo proposto. Este conjunto de partes entram em relação entre si, constituindo as relações internas do sistema. Por outro lado, tanto ca da parte isoladamente, como o conjunto das partes, - sistema inteiro, entram em relações com partes de outros sistemas, constituindo-se nas relações externas do sistema considerado.

Uma das propriedades mais importantes de um sistema é que cada parte do sistema afeta-o no seu todo. Dessa forma, nenhuma das partes de umsis tema pode ser organizada ou dinamizada em sub-sistemas independentes ou isolados. Assim, as partes ou sub-sistemas são instrumentos do sistema maior, devendo ter seus objetivos hierarquizados de tal ma neira que esteja em perfeita harmonia com os objetivos do sistema maior e vice-versa (CAJAS, 1976). 
De acordo com o dito anteriormente, pode mos reunir todas as propriedades identificadas no processo de vigilância epidemiológica e agrupā-las em três grandes grupos, constituindo: o sub-sistema de informação, o sub-sistema de decisão e o subsistema de controle. Estes três grupos, interliga dos, formarão um sistema maior com objetivos definidos, o sistema de vigilância epidémiológica ou sistema de informação, decisão e controle das doen ças transmissiveis e zoonoses, conforme FIGURA 1 (FOSSAERT et al., 1974; OPAS, 1974).

\subsection{SUB-SISTEMA DE INFORMAÇÃO}

O objetivo primeiro para qualquer progra ma de Saúde Pública é conhecer o estado atual da co munidade, onde e quando deve atuar (BERQUo et al., 1972).

A III Reunião Especial de Ministros da Sa ũde, que estabeleceu o Plano Decenal de Saúde (19711980), realizada em outubro de 1972, na cidade de Santiago, Chile, chegou à conclusão que para se es tabelecer um "sistema nacional de saúde para as $\lambda_{-}$ méricas há necessidade de se agilizar e incrementar os sistemas de coleção de informações sobre a 


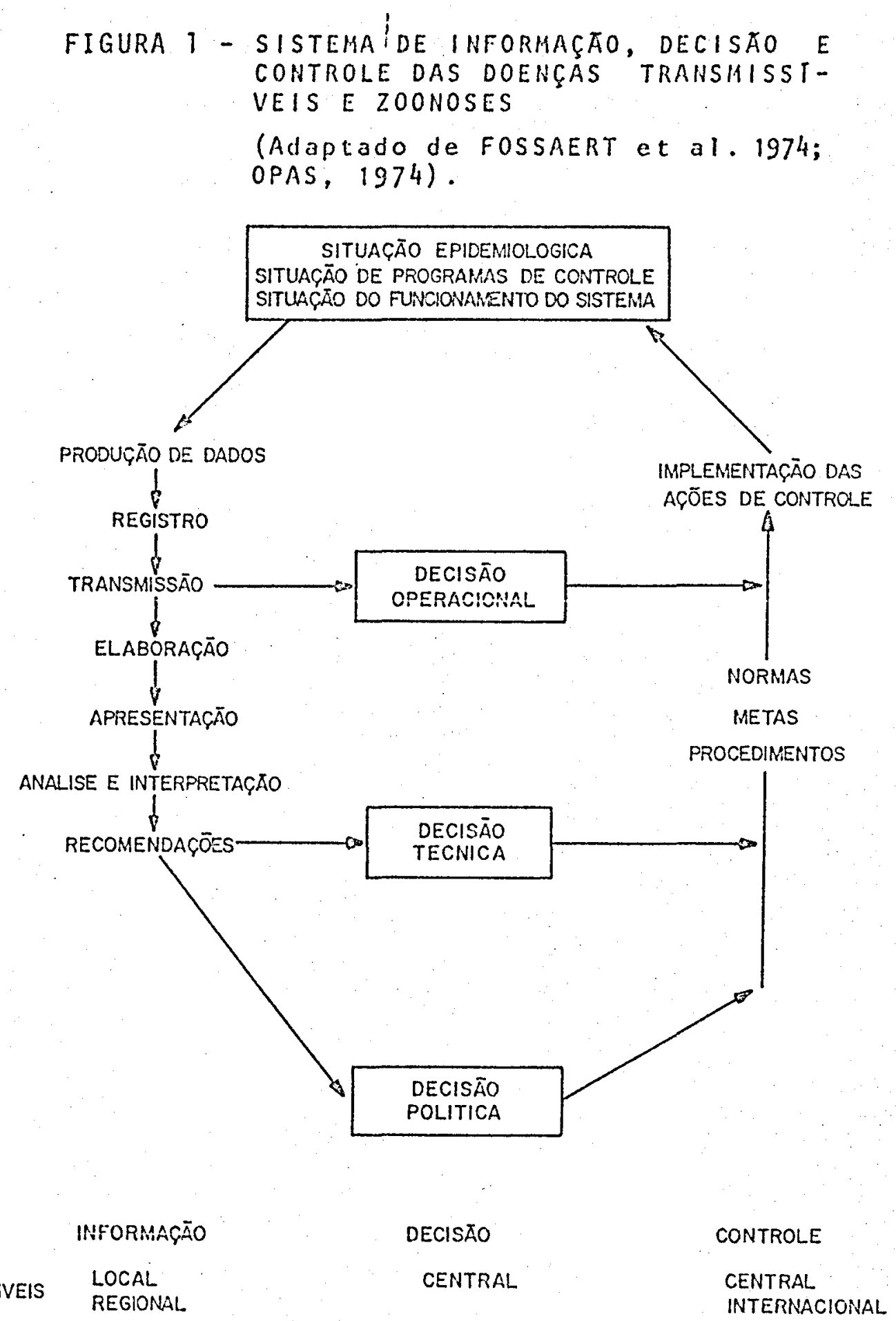


saúde nos diversos países". Para tal, deverá o ad ministrador sanitärio gestionar para obter dados de boa qualidade e em quantidade minima suficiente que permitam aos governos nacionais e organismos inter nacionais tomar decisões quanto ao planejamento, ad ministração e avaliação dos programas locais, regionais, nacionais e internacionais, de saúde $\mathrm{P} \bar{u}-$ blica (OPAS, 1972).

O sub-sistema de informação deverã integrar todos os elementos que participam do processo de vigilância epidemiológica, desde a produção de dados atē a sua anâlise, interpretação e recomenda ções. Por isso, sō será útil, se proporcionar a in formação requerida no momento e lugar que necessitem. Sua rentabilidade dependerá da capacjdade dos serviços de saúde de absorverem e adotarem as medi das recomendadas (FOSSAERT et al., 1974).

O sub-sistema de informação deve gerar no vas informações através de sínteses da situação, com pilações críticas, anālises, correlacionando as dị versas variāveis, resenhas, etc.

As principais funções do sistema de informação, segundo FOSSAERT et al. (1974), são: 
a) manter atualizadas as fontes primärias gerado ras da informação, de forma a acelerar o proces so de conhecimento da situação das doenças trans missiveis e zoonoses;

b) processar, analisar e interpretar os dados;

c) facilitar o intercâmbio de informações entre as diversas regiões do pais e entre paises;

d) possibilitar geração de critērios de decisão que derivem das ações anteriores, para órgãos gover namentais;

e) esclarecer seu público específico e o público em geral no que diz respeito à investigação das en fermidades objeto do programa;

f) em determinadas circunstâncias, dependendo das estruturas existentes a nivel local, regional e nacional, e do seu grau de desenvolvimento, poderá exercer funções executivas de decisão e con trole.

2.1.1. Produção de Dados

A produção de dados è a fonte primária geradora do processo de informação. E a produção de dados que fornece à autoridade sanitária competente a situação da enfermidade em determinado espaço geogrä́fico e temporal." 
Fazem parte da produção de dados, as ati vidades de levantamento de dados e a notificação. o levantamento de dadós, geralmente, atravēs do:

a) uso de informações já registradas - pela obtenção dos dados de mortalidade através dos atestą dos de óbitos (BERQuó et al.,. 1971), incidência de doenças animais através do matadouro (MACIEL \& PAiM, 1961), e dados clínicos, tanto para doenças humanas como animais, através dos registros hospitalares e notificações (OLIVEIRA, 1975);

b) uso de informações não registradas mas existentes - pela aplicação de inquéritos que podem ser questionärios, formulārios ou cédulas (BERQuo et al., 1972), ou inquéritos sorológicos, comumente utilizados para determinar a prevalência de doenças, cujos registros existentes não apresen tam a precisão que se desejaria (OMS, 1969);

c) uso de informações não registradas e não existentes - obtidas por meio de experimentos estri tamente controlados (BERQUO et al., 1972).

A notificação de uma doença é a comunica ção oficial, İ autoridade sanitária competente, da ocorrência de determinadas doenças, transmissive 1 ou de outra natureza, no.homem e nos animais. A no tificação é feita às autoridades sanitárias locais, quando se trata de doenças do homem, às autorida-: 
des de defesa sanitária animal, no caso de doenças dos animais, e àquelas e a estas, nos casos de doenças comuns ao homem e aos animais (OPAS, 1973).

A notificação tanto pode ser feita pelo profissional conhecedor da ocorrência, como por ter ceiros (comunidade), ou pela vigilância exercidape lo serviço oficial (OPAS, 1973). A notificação pe lo profissional ou por terceiros se dá em cumprimento da legislação de cada paìs, quanto às doenças de notificação compulsória. Cada país estabelece a lista de doenças cuja notificação è do seu interesse e compulsória, além de cumprir o Regulamento Sanitário Internacional, no tocante às doenças de notificação internacional (OPAS, 1973). Além da notificação sistemātica de determinadas doenças, exige-se a notificação especial de todas as epidemias ou surtos de doenças, inclusive das que não se encontram na lista de doenças de notificação compulsōria (OPAS, 1973).

No Brasil, a Lei no 6.259 , de 30 de outu bro de 1975, que "Dispõe sobre a organização das a Ções de Vigilância Epidemiológica, sobre o Programa Nacional de Imunizações, estabelece normas rela tivas à notificação compulsōria de doenças e dá oụ 
tras providências", define no seu artigo 89 quem é obrigado a notificar doenças:

"E dever de todo cidadão comunicar à autoridade sanitária local a ocorrência de fato, comprovado ou presumivel, de caso de doença transmissivel, sendo obrigatória a médicos e outros profissionais de saúde no exercicio da profissão, bem como aos responsāveis por organizações e es tabelecimentos públicos e particulares de saúde e ensino, a notificação de casos suspeitos ou confirmados das doenças relacionadas em conformidade com o artigo 7\%" (BRASIL, 1975b).

A notificação por vigilância vai permitir preencher os claros deixados pela não notifica ção das doenças que, embora compulsōria, não tenham sido comunicadas pelos profissionais e laboratörios de diagnóstico. A vigilância é exercida pelos funcionārios dos serviços de Saúde Pública e Saũde Animal.

2.1.2. Confirmação e/ou Registro

Recebida a notificação, a autoridade sa nitâria é obrigada a proceder a investigação epide miológica pertinente para a elucidação do diagnóstico e averiguação da disseminação da doença na po 
pulação sob o foco (BRASIL, 1975).

Dito assim, podemos considerar como uma extensão das atividades de vigilância, a de recorrer aos laboratórios e inquéritos minuciosos para completar os dados fundamentais sobre a incidência das doenças e sua prevalência, obtendo assim infor mações epidemiológicas que a simples notificação de casos não pôde proporcionar (por exemplo, a extensão da infeç̧ão em comparação aos casos da. doença manifesta - OPAS, 1974).

Quando a produção de dados for realizada pelo serviço de vigilância, na ausência de notificações, logicamente não haverá necessidade da confirmação, passando diretamente para a etapa de registro. Registro è a anotação, em formulários prō prios (especiais), dos dados coletados. O registro depende da forma como foram produzidos os dados, daj a necessidade da confirmação, bem como da padronização desses mesmos dados. De uma forma dinâmica, após a obtenção dos ảados, está fase se preocupará em reunir as informações de uma maneira lógica, a fim de permitir a sua transmissão. Cada serviço se encarregará de prover seus agentes locais de formu lärios padronizados (OPAS, 1974). 


\subsubsection{Transmissão}

Rotineiramente, em um serviço de saúde ou de agricultura, as etapas de produção, registro e transmissão dos dados, pertence à agêncià local, levando em conta uma estrutura horizontal do servi ço (FOSSAERT et al., 1974).

A transmissão dos dados consiste na comu nicação do estado de saúde da população local à au toridade regional onde a agência local está jurisdicionada (OPAS, 1974; FOSSAERT et al., 1974). Tal transmissão, dependendo da estruturação existente e interesse e gravidade'da situação, pode ser processada das mais variadas formas: boletins diārios de ocorrências, telegrama, telefone, rádio, rādiotelegrama semanal, boletins quizenais, relatórios mensais, etc. (DEAK, 1973).

Em decorrência dessa transmissão das informações, caberá à autoridade sanitária regional tomar a decisão operativa para a adoção de medidas que o caso requeira (OPAS, 1974). 


\subsubsection{Elaboração}

Com base nos informes das agências 10cais, a regional inicia a elaboração dos dados, que consiste na computação dos mesmos em mápas e/ou pla nilhas jâ previamente determinadas, para servir de base à etapa seguinte (OPAS, 1974; DEAK, 1973).

\subsubsection{Apresentação}

A apresentação dos dados consiste em $\underline{e}$ laborá-los graficamente (tabelas e gráficos) e estatisticamente (calcular taxas especificas, estabe lecer razões e proporções e fixar padrões de compa ração) para a análise e interpretação dos mesmos (OPAS, 1974; DEAK, 1973).

\subsubsection{Anālise e Interpretação}

A análise e interpretação dos dados cor responderá um estudo analítico retrospectivo da si tuação epidemiológica das doenças, com os possiveis avanços e recuos da mesma através do tempo e o alcance das medidas empregadas até o momento, com pa 
drões previamente estabelecidos para sua devida in terpretação. Deste estudo, decorre uma redação de informes e apresentação aos organismos competentes. Tais informes deverão reunir todos os elementos de juizo da situação; os problemas identificados e a interpretação que se lhes dā, a fim de que se possa promover as recomendações e divulgações dos resultados (FOSSAERT et al., 1974; OPAS, 1974).

2.1.7. Recomendação e Divulgação

A recomendação, atravês de uma descrição detalhada da situação confrontada, e a indicação de medidas de controle mais plausiveis que o caso requeira, servirá de insumo para a Decisão Téc nica e a Decisão Política das autoridades superiores a nivel central (FOSSAERT et al., 1974; OPAS, 1974).

Considerando uma estrutura horizontal, a agência Regional continuará informando a Central so bre o desenrolar dos acontecimentos, durante a exe cução das medidas de controle decididas pela central. No caso de uma estrutura vertical, a comuni cação com a Central será realizada diretamente pela agência local executora (FOSSAERT et al., 1974). 
A divulgação dos resultados incluirá os serviços de saúde e outros, inclusive organismos in ternacionaịs, fornecendo detalhes sobre a situação epidemiológica do país, estado ou ārea submetida à vigilāncia (FOSSAERT et al.; 1974). Todavia, essa divulgação ainda é restrita a organismos, não se permitindo. a retro-alimentação (feed-back) às fontes primārias de informação (OPAS, 1974).

As atividades aqui descritas, interligadas desde a produção dẹ dados atē à sua divulgação, constituem, pois, o sub-sistema de informação.

2.2. SUB-SISTEMA DE DECISÃO

Não vamos entrar na problemātica de tomada de decisão que o planejamento PERT, Programação Linear e outros, oferecem, nem tampouco vamos discutir niveis de propriedades de decisões, ou ainda, quando se toma decisões ou quem as toma, u ma vez que fugiria ao nosso trabalho. Interessa-nos, nesta exposição, estabelecer tão somente as linhas de comunicação e algumas funçõ்es dentre as diversas partes e sub-sistemas que compõem o sistema de vigilância epidemiológica. 
Neste procedimento, como já foi descrito anteriormente, o sub-sistema de decisão depende, fun damentalmente, do sistema de informação.

2.2.1. Decisão Operacional

A decisão operacional, devido à rapidez com que deverá se processar, será responsabiliz dade da agência regional que atravēs de medidas de controle jā padronizadas, indicarā quais serão as mais efetivas no caso, dará o apoio logístico ne cessārio e se comunicará com o sub-sistema de controle para que o mesmo possa implantar as ações de controle (OPAS, 1974).

\subsubsection{Decisão Técnica}

A decisão é tomada a nível central uti Iizando os critērios de avaliação dos programas. Segundo DEAK (1973), tais critérios são:

- acompanhamento técnico;

- acompanhamento físico;

- acompanhamento financeiro.

\section{BIBLIOTECA}


O acompanhamento técnico visa estudar o comportamento da enfermidade, durante e após o desenvolvimento do programa, pelas informações de cu彑 nho panorâmico (atravếs de informes semanais) e pe las informações tēcnicas, de carāter epidemiológico avaliativo (vigilância e confirmação de dados). O acompanhamento físico verifica as execuções das atividades programadas como: trabalhos de campo, disponibilidade de produtos biológicos, aplicação de vacinas, etc. O acompanhamento finarceiro preten de avaliar se os recursos financeiros dispendidos nas atividades estão se revertendo em benefícios econômicos e sociais que compensem sua aplicação. são os chamados custos sociais de um programa sani tário.

A Organização Mundial da Saūde (OMS) vem estimulando o estudo e formação de profissionais em matéria de avaliação sócio-econômica das zoonoses e formulação de modelos matemáticos de doenças dos animais, notadamente na Universidade de Reading (Reino Unido) e na de Melbourne (Austrália) (OMS, 1974). 


\subsubsection{Decisão Política}

A decisão politica se baseia nos infor mes da decisão têcnica e nas recomendações emanadas do sub-sistema de informação. Consiste na decisão superior do sistema, da qual dependem as decisões técnica e operativa, e o sub-sistema de con trole.

A decisão política virá dar uma operacio nalização global e continuidade ou não às atividades até aqui executadas (OPAS, 1974).

2.3. SUB-SISTEMA DE CONTROLE

Em linhas gerais, o sub-sistema de controle, pelos informes obtidos do sub-sistema de de cisão, elaborarā procedimentos (sequência das ações dirigidas para metas), normas e metas; e a implementação das ações de controle para melhor atender ao programa (OPAS, 1974).

As ações de controle aqui nomeadas estão dirigidas para melhor eficiência da execução do pro grama, e não como mecanismo de regulação do siste- 
ma em todas as suas partes, cabendo neste caso ao sub-sistema de decisão, que deverá ter sob sua administração recursos reais ou potenciais suficientes de prover capacidade de auto-regulação do sistema (CARVALHO, 1976).

Somente a partir da implementação das ações de controle é que a fonte primäria de produção de dados tomará conhecimento real e global da situação epidemiolögica existente a nível local, re gional e nacional. Esta fase é importantíssima pa ra manter a fonte geradora de dados, permanentemen te motivada e conhecedora da situação existente. Tal prática permite a quem informou, saber realmen te o valor da sua informação (OPAS, 1974). 
3. CONSIDERAÇOES SOBRE A ATUAL SITUAÇÃO DOS SISTEMAS DE. INFORMAÇOES DE SAODE 


\section{CONSIDERAÇOES SÓBRE A ATUAL SITUAÇÃo DOS SISTEMAS DE INFORMAÇOES DE SAUDE}

\subsection{NAS AMERICAS}

Os modernos avanços e desenvolvimento das ciências vêm proporcionando meios e mëtodos ca d a vez mais eficientes para a prevenção, controle e ex radicação das doenças. Todavia, estes consideráveis progressos científicos postos à disposição, ainda não foram absorvidos ou assimilados pela maio ria dos países sub-desenvolvidos e pelos chamados paises em desenvolvimento (OPAS, 1972). Isto, tal vez, seja devido mais às sérias dificuldades de or dem cultural, operativa, econômica e social, que a problemas básicos, o que tem tornado difícil e ārduo os progressos neste campo (OPAS, 1974).

A falta de eficientes serviços de vigilância epidemiológica parece sèr, em maior ou menor grau, a fonte principal de erro que impede conhecer oportunamente as caracteristicas epidemioló 
gicas das doenças, contribuindo para o desconhecimento total ou parcial do processo dinâmico, for ças ou fatores, que intervêm na propagação da infecção e em que medida esta se propaga, dificultan do os organismos nacionais e internacionais de reconhecer e analisar devidamente o problema. (OPAS, 1974).

Em pesquisa recente, ROMERO \& VALVERDE (1975) constataram que na maioria dos países centro-americanos não existem serviços integrados de vigilância epidemiológica e são limitados os conhe cimentos que se têm sobre as doenças transmissiveis, sua distribuição, ecologia, etc. Tal proble mātica foi amplamente discutida na III Reunião de Ministros da Saúde (OPAS, 1972), quando então se su geriu criar e manter unidades de vigilância epidemiológica de acordo com a organização nacional e a estrutura de cada país, a fim de se ter um conheci mento permanente das caracteristicas epidemiológicas dos problemas de saúde e os fatores que os con dicionam, para poder atuar oportunamente.

Os sistemas administrativos relacionados com as doenças que se devem notificar e os procedi mentos necessārios para tal, variam muito de uma re 
gião para outra, e de um país para outro (OPAS, 1972).

O National Câncer Institute do Serviço de Saūde püblica dos EUA, interessado em desenvolver atividades de pesquisa em medicina comparada, incluiu no início da década de 60 , projetos de estudo prospectivo e promoção da participação veteriná ria na pesquisa do câncer, principalmente através de dados de ocorrência. Porém, tal programa se es barrou em uma série enorme de dificuldades, em que a principal se revelou ser uma deficiência total de dados clinicos veterinärios confiäveis sobre câncer, bem como em outras àreas da pesquisa veteriná ria (TJALMA et al, , 1964).

Desta forma, consciente do problema, e com a colaboração da Escola de Veterinária da Universidade de Michigan (EUA), de veterinārios parti culares e de outros organismos daquele país, o National Cancer Institute elaborou um protótipo completo de uma nomenclatura padrão para doenças e operações veterinārias (TJALMA et al., 1964).

Levando em consideração que condições se melhantes devem ser especificadas e codificadas em 
termos semelhantes para assegurar a comparabilidade e a categorização analítica, tal nomenclat u r a (Standard Nomenclature for Veterinary Diseases and Operations - SNVDO) não é uma lista alfabética de doenças e operações animais. Foi planejada para codificar todas as doenças dos animais domësticos, contendo seções sobre: topografia, etiologia, Indice especificado por doenças, classificação de pro cedimentos operativos, código de operações, e índi ce de operações. Todavia, não foram incluídas doenças exóticas para os EUA, nem tampouco de animais anfíbios e selvagens. Esta nomenclatura, porēm, foi elaborada de tal forma que permitirá a adição dessas categorias nas diversas seções, sem prejuizo da estrutura uniforme do código (TJALMA et al., 1964).

Vărias instituições dos Estados Unidos e Europa têm adotado este sistema, com grande suces so, e se prevê que outras instituições de diversos países o adotarão (TJALMA et al., 1964).

Adaptações dessa nomenclatura foram tentadas no México (FERNANdez, 1976)* e Uruguai (NEWSAM, 1976)**, porēm sem sucesso, o que fez os interessą

\footnotetext{
* Fernandez, R.F. - comunicação pessoal. Mëxico, 1976.
} ** NEWSAM, I.D. - comunicação pessoal. Uruguai, 1976. 
dos abandonarem o programa.

Na Inglaterra o "Ministry of Agriculture, Fisheries and Food", primeiramente adotou o sistema de nomenclatura americana para as doenças animais (SNVDO), em seu projeto original VIDA. Porēm, devido à sua complexidade foi abandonado em provei to de um sistema inglès próprio, o projeto VIDA II. Este projeto é um sistema para registrar os diagnósticos realizados em cada um dos 33 laboratórios regionais de diagnóstico veterinário da Inglaterra, sob a supervisão do Laboratōrio Veterinārio Central, do Ministério da Agricultura daquele país. A lëm deste sistema, os ingleses desenvolvem um outro especifico para as zoonoses, estando ainda em sua fase inicial trabalhando somente com as estatísticas de morbidade referentes às salmonela (DAVIES, 1976)* .

A Organização Mundial da Saúde (OMS), a Organização de Alimentação e Agricultura das Nações Unidas (FAO) e a Organização Internacional de Epizootias (OIE), têm elaborado conjuntamente, O Anuá rio de Saúde Animal, dando uma visão global do aspecto sanitário dos rebanhos de quase todos os paí ses do mundo. Muito embora as notificações deixem a desejar, tais informações são indispensāveis pa-

* DAVIES, G. - Comunicação pessoal. Surrey, England, 1976. 
ra o planejamento das ações de saúde nesses países (OMS, 1974). A Organização Mundial da Saūde tambēm publica o WORLD HEALTH STATISTIC REPORT, em in glès e francês, fornecendo dados mensais sobre a prevalência das principais zoonoses (OMS, 1974).

Analisando alguns aspectos do sub-sistema de informação para os paîses das Américas, pode mos dizer que a supervisão da coleta e elaboração dos dados é limitada ou praticamente inexiste, na maioria deles (OPAS, 1972).

No tocante à morbidade, a metade dos paI ses possuem sistemas nacionais de informação sobre doenças transmissiveis para doenças humanas a cargo do Ministério da Saúde (OPAS, 1972). Porém, sua utilização é deficiente, com a difusão dos dados pa ra retro-alimentação totalmente inexistente na maio ria desses países.

Há ừ interesse crescente em se registrar, transmitir, eleborar e apresentar os dados sob for ma de tabelas, gráficos, etc. Tal interesse, porém, permanece nessa etapa, levando a crer que há 
uma crise conceitual sobre a real utilização desse sistema em saủde animal (ASTUDILLO, 1972).

No que diz respeito às zoonoses de primeira ordem, hâ um total descompasso na fixação de prioridades, entre os Ministérios envolvidos, bem como não estão organizados bons sistemas de cap tação e processamento de dados, dificultando sobre maneira a execução dos programas de combate às zoo noses (OPAS, 1972).

Estimativas conservadoras indicam que so mente a febre aftosa, brucelose, raiva, tuberculose bovina, cisticercose e hidatidose, provocam um prejuizo de centenas de milhões de dólares por ano, reduzindo a oferta de proteinas na ordem de $25 \%$, proteínas essas essenciais para o desenvolvimento normal de menores de 5 anos, cuja mortalidade se si tua em 45\% do total de óbitos anualmente nas Améri cas (OPAS, 1972; HORWITZ, 1970).

Estas cifras, a grosso modo, nos dão uma idéia do valor do combate à febre aftosa e às zoonoses que afligem nossos rebanhos, com reflexos na organização social e econômica da comunidade. 
Vale ressaltar os prejuizos causados pelas zoonoses, em termos de população humana (OMS, 1969) :

- perdas de vida;

- incapacidade intelectual (má nutrição);

- perdas de horas de trabalho;

- gastos hospitalares;

- redução de capacidade de trabalho.

O sub-sistema de informação em zoonoses, em termos de estatisticas vitais, desempenha um pa pel preponderante para a base de estudo desses pre juizos e consequlente determinação de prioridades governamentais para o combate a essas enfermidades.

\subsection{NO BRASIL}

A situação do sub-sistema de informação em zoonoses no Brasil, segue a maioria dos países latino-americanos. E notōria a desinformação e a falta de integração entre os diversos órgãos pübli cos e privados, que poder-se-ia dizer, estão interessádos no problema.

Atravês de consultas formuladas por car- 
tas, bem como entrevistas pessoais com algumas entidades do país, verificou-se que são vārias as ox ganizações pübli.cas, que cuidam de um modo ou de oụ tro, de estatisticas relacionadas a zoonoses.

Primeiramente, temos o Ministērio da saū de, a quem, pela Lei no 6.229 , de 17 de julho de 1975, que "Dispõe sobre a organização do Sistema Na cional de Saúde", compete formular a politica nacional de saúde e promover ou executar ações prefe rencialmente voltadas para as medidas e os atendi mentos de interesse coletivo.

- Sistema Nacional de Saúde constitui o complexo de serviços do setor público e privado, vol tado para as ações de intereśse da saūde, abrangen do as atividades que visem à promoção, proteção e recuperação da saūde (BRASIL, 1975a).

o Ministério da Saúde, pelo Sistema Nacional de Saũde, identifica seis āreas programäticas fundamentais, concebidas em novas bases estruturais, tēcnicas e administrativas, com o propósito de modernizar o Setor Saúde do País para alcançar maior coerēncia e harmonia de decisões (LEMOS, 1973). 
Para tal, pretende-se imprimix ao setor uma centralização normativa e descentralização exe cutiva, visando o incremento da produtividade e mai or rentabilidade dos investimentos, evitando-se, des ta forma, a dispersão de recursos, a repetição des necessária e às vezes competitiva de atividades e serviços, .e outras distorções que se traduzem, na prática, em maior incidēncia e prevalēncia de enfer midades controláveis, altas cifras de obituário, notadamente o infantil, e incapacidade temporária ou definitiva para o trabalho (LEMOS, 1973).

Através da Superintendência de Campanhas de Saúde pública (SUCAM), o Ministērio da Saúde su perintende várias campanhas de saúde püblica desen volvidas nos Estados da Federação: Malárịa; DoenÇa de Chagas; Esquistossomose; Febre Amarela; Peste; Bouba-Bócio Endêmico-Tracoma; Leishmanioses.Com exceção para as Leishmanioses, as demais estão individualizadas, isto é, têm responsáveis pelos pro gramas (MARQUES, 1975)*.

Por delegação do Ministērio da Saũde, a Fundação de Serviços de Saúde püblica (FSESP), órgão vinculado a esse Ministério, coordena, contro-

* Marques, A.C. - Comunicação pessoal. Brasília, DF, 1975. 
la e avalia os programas Nacionais de Imunizações, Vigilância Epidemiológica, Controle e Profilaxia de várias doenças transmissiveis, inclusive a raiva (GO MES, 1976)*. A Fundação SESP publica o Boletim de No tificação Semanal de Doenças Transmissiveis, com da dos fornecidos pelas unidades sanitárias de cada Es tado, a nivel de município, das doenças de notificação obrigatōria e sob vigilância (Cólera, Febre Amarela, Peste e Varíola; Hanseníase, Tuberculose e Malāria; Coqueluche, Difteria, Febre Tifóide, Po liomielite, Raiva, Sarampo e Tétano; Doença meningocócica, Meningite sem especificação), incluindo notas epidemiológicas sobre vārias doenças transmis siveis.

Nos Estados, seguindo o Decreto-Lei no 200/67, por delegação, as Secretarias de Saúde são executoras da Politica Nacional de Saúde, adaptando-a no que couber às características regionais de cada Estado, sem, contudo, ferir os princípios bäsicos que norteiam essa Politica.

Alēm do Instituto Nacional de Previdência Social (INPS), que lida com estatísticas de atendimentos e recursos, da Fundação IBGE e dos Departa-

* GoMes, F.J.P. - Coniunicação pessoal. Rio de Janeiro, 1976. 
mentos Estaduais de Estatística que lidam com esta tísticas de população (censo) e registro civil, às secretarias de saúde competem coletar, processar, analisar, publicar e utilizar os dados quanto a re cursos, atendimentos e morbidade em saūde pūblica (BRASIL, 1971). No Estado de são Paulo, a Coordenadoria de Saúde da Comunidade, da secretaria de sạ ũde, cabe coletar esses dados atravēs de formulários pröprios que são preenchidos pelas unidades sa nitārias locais, e enviados às administrações regionais e central daquela secretaria.

No Setor de Agricultura temos o Ministério da Agricultura, que através do Departamento $\mathrm{Na}$ cional de Produção Animal - Divisão de Defesa Sani tária Animal, dita a política nacional de saúde animal, dando normas e coordenando as atividades nes te Setor. As Secretarias de Agricultura Estaduais, seguindo as diretrizes do Decreto-Lei no 200/67, são os órgãos executores dessa política (BRASIL, 1967), a quem compete coletar, processar, analisar, publi car e utilizar os dados referentes a recursos, atendimentos e morbidade em saúde animal.

o Centro Brasileiro de Estatísticas Agro pecuārias, ōrgão da Fundação IBGE, preocupa-se em 
obter informações relativas à quantidade de animais vitimados face diversas causas que redundem na per da de cabeças em vārias regiōes do Brasil, por mētodo estatistico de amostragem probabilística (EHLERS, 1976)*.

- Centro Brasileiro de Estatísticas Agro pecuárias, foi criado em 1968, como Departamento es pecializado, destinado ao planejamento, à realização, à coordenação dos levantamentos, estudos, pes quisas, e análises no campo das estatísticas agropecuārias continuas a nível Municipal (Fundação IBGE, 1976).

Segundo EHLERS (1971), tendo em vista a reformulação das estatísticas agropecuãrias, O Pla no Bāsico Nacional de Aperfeiçoamento de Estatistí cas Agropecuárias realizou o diagnóstico e definiu as diretrizes a serem observadas pelos órgãos produtores de estatisticas agropecuárias, bem como pro moveu a criação da Comissão Especial de Planejamen to, Avaliação.e Controle das Estatísticas Agropecu ārias (CEPAGRO), constituída por três representantes da Fundação IBGE, três representantes do Minis. têrio da Agricultura, e presidida pelo Diretor-Su-

* EHLERS, R.F. - Comunicação pessoal. Rio de Janeiro, 1976. 
perintendente do Instituto Brasileiro de Estatisti ca, órgão da Fundação IBGE.

Vemos, assim, que os primeiros passos já foram dados para promover a coordenação do setor. Porēm, como às estatîsticas agropecuārias interessa mais o problema econômico, estabelece-se um vazio para as relacionadas à saúde (zoonoses).

Na tentativa de preencher, em parte, essa lacuna, o Programa Nacional de Profilaxia da Rai va estabeleceu as bases para a criação de uma Coor denação Nacional de Profilaxia da Raiva, com repre sentantes do Ministério da Saúde, do Ministērio da Agricultura, CEME, OPAS/OMS (F/GURA 2). Também su gere a criação de Comissões Estaduais, visando a pa dronização de mëtodos de atuação. Em São Paulo, o Decreto no 2.862 , de 21 de novembro de 1973 , insti tuiu junto à Coordenadoria de Serviços Técnicos Es pecializados, da Secretaria de Estado da Saúde, a Comissão Permanente de Controle da Raiva, com a se guinte composição: quatro representantes da coordenadoria de Serviços Técnicos Especializados, sen do um representante do Gabinete do Coordenador, um do Instituto Pasteur, um do Instituto Butantan e um do Instituto de Saúde; três representantes da 
PROGRAMA NACIONAL DE PROFILAXIA DA RAIVA

Fluxograino

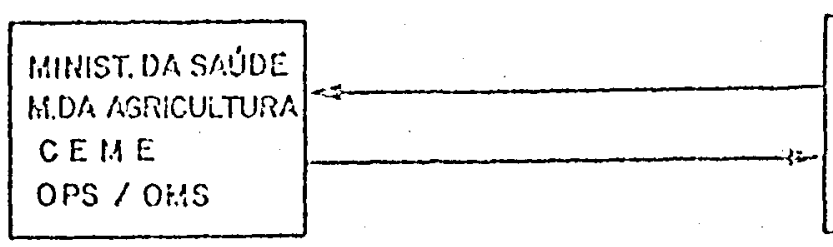
couinomargo IMCOIONAL

COHPONEHTES

DA

cosiss

ESTADUAL

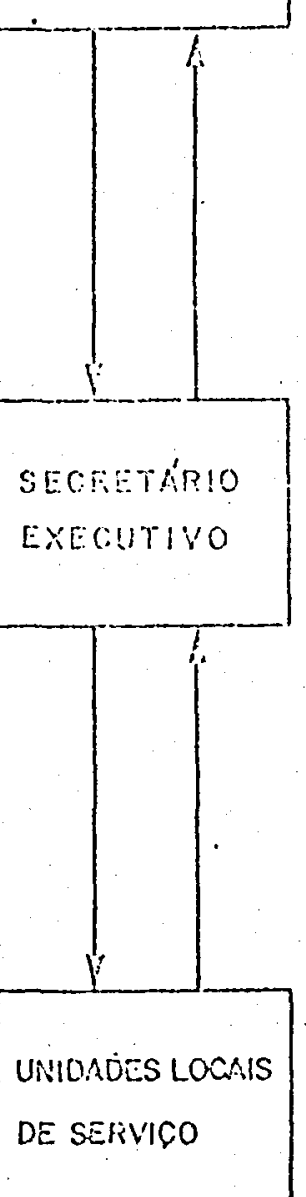


Divisão Centro de Controle de Zoonoses da Secretaria de Higiene e Saúde, da Prefeitura Municipal de São Paulo, sendo um deles, seu Diretor; um representante da Coordenadoria de Saúde da Comunida de, da Secretaria de Estado da Saúde; um representante do Instituto Biológico da Secretaria de Agricul tura; um representante da Coordenadoria de Assistência Técnica Integral da Secretaria de Agricultü ra; um representante da Faculdade de Medicina Veterinäria da Universidade de São Paulo; um representante da União Protetora de Animais de São Pau10.

Ainda na tentativa de se promover algum tipo de integração entre os setores de Saúde e Agri cultura, foi recentemente criado pelo Ministério da Agricultura, o Instituto Nacional de Saúde Animal (INASA), com sede em Pedro Leopoldo, Minas Gerais, que entre outras atribuições, pretende realizar $\circ$ diagnóstico de vārias enfermidades animais, inclusive zoonoses, e servir de centro de Referências e de apoio, à semelhança do Centro panamericano de zo onosis (CEPANZO), da OPS/OMS, localizado na Argentina.

No sentido de centralizar e coordenar com 
maior eficiência as ações de controle das zoonoses foram criados em São paulo e Rio de Janeiro, centros específicos de controle das zoonoses.

A Divisão centro de controle de zoonoses, da Secretaria de Higiene e Saúde da prefeitura Municipal de São paulo (fIGURA 3), criada pela lei Mu nicipal no 8.108, de 02 de setembro de 1974, vem da evolução dos então Serviço de Prevenção da Raiva (criado pelo Decreto no $7.835 / 68$ ) e do Serviço de Controle de Roedores (Decreto 9.850/72). Esta Divisão conta atualmente com recursos humanos, materiais e financeiros aptos a cumprir o que the compete:

"I - Promover e executar a prevenção das zoonoses;

II - planejar e executar programas de pesquisa vi sando a prevenção das zoonoses;

III - planejar e executar programas de preparo e aperfeiçoamento do pessoal técnico e auxilí ar;

IV - estabelecer convênios com instituições oficiais e particulares em matēria de sua competēncia;

V - promover reuniões de estudo e debate sobre problemas de zoonoses" (SAOO PAULO, munici pio, 1974). 
Divisáo CENTRO de CONTROLE dE zOONOSES

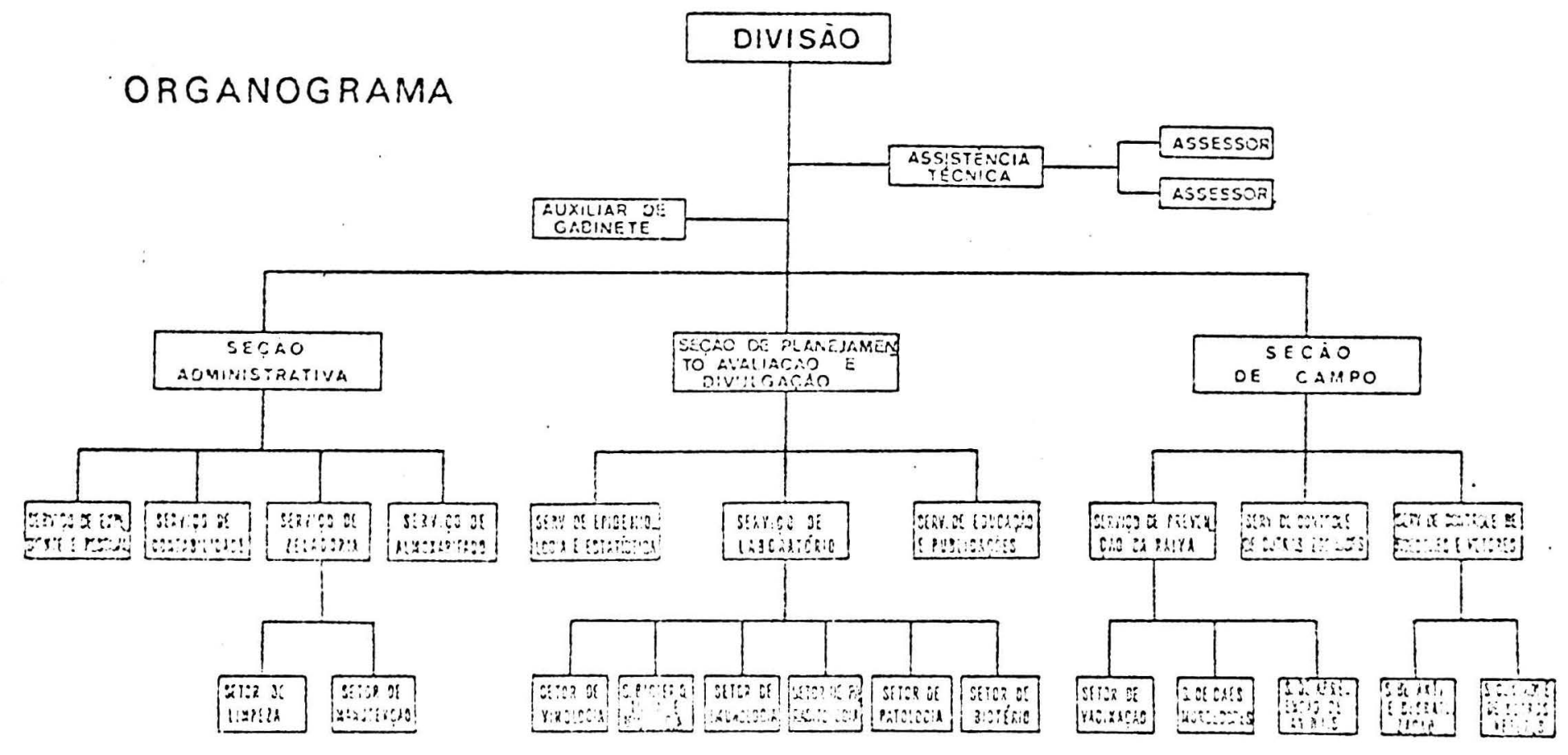


A fusão dos Estados do Rio de Janeiro e Guanabara, gerou a necessidade de uma completa reformulação administrativa, advindo, entre outras, a criação do Centro de Medicina Veterināria, da Secre taria de Saúde, à semelhança do Centro de Controle de Zoonoses da Prefeitura Municipal de São Paulo.

De qualquer forma, como veremos adiante; os esforços são ainda limitados, não havendo um a coordenação efetiva e eficiente para o sistema de informação, decisão e controle das zoonoses para to do o Brasil.

Considerando-se os Ministërios da Saũde e Agricultura e as Secretarias de Saúde e Agricultura, como os principais interessados e utilizadores das estatísticas de saūde em zoonoses, analisa remos os principais aspectos relacionados com osis tema de informação, decisão e controle das zoonoses no Brasil, com referência aos setores de saúde Humana e Saúde Animal.

3.2.1. Produção de Dados

As informações sobre a ocorrência de zo 
onoses em saúde humana provêm basicamente de regí tros de hospitais públicos e privados, serviços am bulatoriais, laboratórios de diagnóstico e consultórios médicos, além das investigações realizadas pelo serviço de vigilância oficial (OMS, 1969; FOS SAERT et al., 1974; OPAS, 1974).

As notificações sobre a ocorrência de do enças, de um modo geral, são incompletas e viciadas, visto que não cobrem todas as doenças; alëm da reconhecida falha de notificação, mesiıo quando com pulsória (LAURENTI, 1971).

No Brasil, a Lei de Vigilância Epidemiológica (BRASIL, 1975b) dispõe sobre doenças de notificação compulsória, e no Estado de São Paulo, o Decreto no 52.503/70, estabelece como doenças de no tificação obrigatōria, dez zoonoses: Febre Amarela; Peste; Arboviroses; Bruceloses; Doença de Chą gas; Leptospiroses; Raiva humana; Riquetsioses; Tü berculose; Carbūnculo.

Todavia, o sistema de informação, deci são e controle se perde na fase inicial que é a pro dução de dados. Não se pode avaliar de uma forma conclusiva a ocorrência de zoonoses no homem. Isto 
porque, a falta de notificações às autoridades com petentes, è uma constante. Exemplo disto temos nos dados obtidos em trabalho escolar realizado porSIL VEIRA (1974) sobre a ocorrência (registro) de casos humanos de zoonoses, en fonte oficial (secreta ria da Saúde do Estado de São Paulo) e alguns hospitais da cidade de São Paulo, compreendendo o periodo de 1969 a 1973. As informações prestadas pe las citadas fontes são as constantes dos QUADROS 1 e 2, referentes às mesmas doenças e os mesmos períodos.

No tocante à saúde animal, o sistema de informação está todo ele praticamente calcado no di ploma bāsico da Defesa Sanitária Animal do Brasil, que é o Decreto no 24.548, de 03 de julho de 1974, que aprova o Regulamento do Serviço de Defesa Sani tāria Animal. Tal Decreto, em seu artigo 61, expressa como doenças de notificação obrigatōria, pas síveis da aplicação de medidas de defesa sanitária animal, 27 enfermidades, das quais nove são zoonoses: Raiva; Tuberculose; Carbünculo; Bruceloses; Sal moneloses; Pasteureloses; Tripanossomoses; Monmo (ti do como extinto no Brasil); Encefalites; Psitacose (sem dados de ocorrência); Sarnas. 
QUADRO 1 - CASOS HUMANOS DE ZOONOSES NO ESTADO DE SATO PAULO, DURANTE 1969-1973

\begin{tabular}{|c|ccccc|c|}
\hline Zoonoses & 1969 & 1970 & 1971 & 1972 & 1973 & TOTAL \\
\hline Leptospirose. & 59 & 38 & 70 & 87 & 52 & 256 \\
Brucelose ... & - & - & - & - & 4 & 4 \\
Teníase ..... & - & - & - & - & - & - \\
Cisticercose. & - & - & - & - & - & - \\
Toxoplasmose.. & - & - & - & - & - & - \\
\hline
\end{tabular}

FONTE: Coardenadoria de Saúde da Comunidade.

QUADRO 2 - CASOS HUMANOS DE ZOONOSES NO ESTADO DE SAO PAULO, DURANTE 1969-1973

\begin{tabular}{|c|rrrrr|r|}
\hline ZOONOSES & 1969 & 1970 & 1971 & 1972 & 1973 & TOTAL \\
\hline Leptospirose.. & 37 & 41 & 8 & 12 & 8 & 106 \\
Brucelose .... & 2 & 1 & 1 & 1 & - & 5 \\
Teniase ..... & 58 & 36 & 46 & 38 & 36 & 210 \\
Cisticercose.. & 19 & 26 & 18 & 41 & 13 & 117 \\
Toxoplasmose.. & 90 & 89 & 50 & 60 & 46 & 329 \\
\hline
\end{tabular}

FONTES: Hospital do Servidor Público de São Paulo Hospital da Santa Casa de São Paulo Hospital das Clínicas de São Paulo Hospital São Paulo

IN: Disciplina Saūde Pública Veterinäria, FSP/USP. 
Em saūde animal as informaçōes provêm prin cipalmente do serviço oficial de defesa sanitāria animal (vigilância exercida pelos veterinārios e au xiliares), por terceiros (vizinhos das propriedades onde ocorre o focol, por veterinários particulares e pelos proprietários dos animais. o ültimo è a forma mais dinâmica da produção de dados em agricultura e vem sendo estimulado e motivado pelo Programa Nacional de Saúde Animal (PRONASA).

o PRONASA está em fase de implantação, com - apoio técnico e financeiro do Banco Interamerica no de Desenvolvimento (BID). Este Programa visa controlar a Febre Aftosa, Raiva e Brucelose em todo país, com ações direcionadas mais para a espécie bovina.

- PRONASA vem aproveitando a estrutura de serviço oferecida pelo Plano Nacional de Combate à Febre Aftosa (PNCFA), desenvolvido durante oquatriê nio 1972-1975 em sete Estados da Federação (RS, PR, SC, SP, MG, BA, ES). O PNCEA, com o apoio do BIDe da OPAS/OMS, através do Centro Pan-Americano de Fe bre Aftosa, localizado no Rio de Janeiro, implantou o que denominamos sistema de informação, decisão e controle da Febre Aftosa. Lamentavelmente, po 
rêm, até o momento, não conseguiu estabelecer o cí clo completo do sistema, permanecendo muitas das informações a nîvel somente de anälise. Todavia, hâ informações como as de ocorrēncia de focos, vacinação de bovinos e produção de vacinas que são bem aproveitadas em todo o sistema. Vale dizer que o sistema vem se aperfeiçoando.

Ainda com relação à saúde animal, as informações de incidência de algumas zoonoses são ob tidas, através dos registros em matadouros-frigori ficos. Porém, estas informações, de grande valia, não são aproveitadas convenientemente na prática. Não hã entrosamento de informações e ações entre o serviço de defesa sanitária e o serviço de inspeção veterināria federal, embora ambos sejam do mes mo Ministêrio (Agricultura) e a despeito de vārias tentativas realizadas.

\subsubsection{Registro}

A zoonose que o setor saúde se preocupa por excelência, com ampla participação do médico-veterinārio e outros profissionais de saúde, é a Raiva. Na epidemiologia dessa zoonose no Brasil 
é a espécie canina quem ocupa posição de destaque. Os formulārios: Ficha individual de tratamento an ti-rábico humano (ANEXO I); Ficha de informação e pidemiológica de casos de Raiva humana (ANEXO II); e Ficha de informação epidemiológica de complicações neuroparaliticas humanas associadas com a vacinação anti-räbica (ANEXO III), são recomendados pelo Programa Nacional de Profilaxia da Raiva. Tal Programa estabelece as diretrizes, responsabilidades institucionais e os fluxos de coleta, análise e distribuição de dados (BRASIL, 1973).

Os formulários: Ficha comprovante de va cinação anti-rábica canina (ANEXO IV), e Ficha residencial para inquérito da população canina (ANExO V), são utilizados pelos municípios que desenvolvem campanhas de vacinação contra a Raiva canina, sob a supervisão da Coordenação Nacional da Pro filaxia da Raiva (BRASIL, 1973).

Fora o Programa Nacional de Profilaxiada Raiva, que a nosso ver tem condições de desenvolver um sistema de informação, decisão e controle para a Raiva, as demais zoonoses estão, no Setor Sa úde, desarticuladas. 
No Setor Agricultura, o Decreto n8 24.548 de 03 de julho de 1934, estabeleceu o formulário "Certificado de Inspeção Sanitäria Animal" (ANEXO VI), que foi um dos primeiros veiculos a estabelecer o fluxo de informações em saūde animal, prin cipalmente para a variāvel deslocamento de animais (trânsito). com reflexos em outras variāveis como vacinações e exames realizados. Tal Certificado, por norma, só poderia ser expedido após ter si do constatado por autoridade competente (médico-veterinārio do serviço oficial), que os animais estavam em perfeito estado de higidez. Na prática, po rém, o Certificado é fornecido mediante a exigência da apresentação do atestado de vacinação e/ou atestado negativo, para as doenças mais prevalentes para cada espécie animal.

Ao analisarmos alguns formulärios para re gistro de dados em saúde animal devemos situar dois aspectos: dados relativos à morbidade e mortalida de e dados relativos a atendimentos.

No que diz respeito aos dados relativos à morbidade e mortalidade, temos a Ficha nosogräfi ca (ANEXO VII) onde se registra a ocorrência mensal das doenças animais, tanto de notificação obri 
gatōria ou não. Esta Ficha, preenchida a nivel lo cal, é processada a nível central, servindo de base para a elaboração de informes aos organismos inter nacionais.

o Boletim Informativo de Ocorrência de Febre Aftosa-BIOFA (ANEXO VIII) e o.Boletim Infor mativo de Encerramento de Surto de Febre Aftosa BIESFA (ANEXO IX) são formulārios que estão sendo utilizados a nivel de campo pelo PNCFA para o registro de dados sobre morbidade e mortalidade em Fe bre Aftosa.

O formulário: "Ocorrência de Raiva Cani na - Notificação (ANEXo X) é utilizado pela Divisão Centro de Controle de Zoonoses, da Prefeitura Municipal de São Paulo, para conhecer a ocorrência da Raiva Canina na área desse município. E preenchido, principalmente, pelo Instituto Pasteur, pela pröpria Divisão e por outras instituições, inclusi ve clinicas veterinărias. Essa Divisão tambëm usa a Ficha de Entrada do Animal (ANEXO XI; para o caso específico de mordeduras na população humana, com dados sobre o animal mordedor, a ocorrência da mordedura e o diagnóstico. 
As Cisticercoses, Hidatidose e Tuberculo se têm seus registros praticamente limitados ao Ser viço de Inspeção Federal. Considerando, ainda, a Tuberculose bovina, sabe-se que tuberculizações são realizadas, porēm, seus resultados, na maioria das vezes, não são registrados nem transmitidos ao örgão competente, carecendo de formulários próprios e de uma coordenação central. A mesma situação, es tá, a nosso ver, para as demais zoonoses.

Observando-se os programas de saúde animal desenvolvidos até o presente (PNCFA, p. ex.), vê-se que há uma tendência de se registrar mais atendimentos que morbidade. Assim, dä-se mais vaIor ao número de vacinações realizadas que o nível de proteção que essa vacinação conferiu a campo. Dá-se mais valor ao número de palestras realizadas (avaliação administrativa) que o efeito produzido ou aumento de conhecimentos ou motivação dos parti cipantes (avaliação educativa).

Em resumo, observa-se de um modo geral, deficiências nas várias fases do sub-sistema de in formação em zoonoses, não permitindo ao administra dor sanitārio se utilizar dessas informações, adequadamente, a nível confiável, para as suas decisões técnica e política. 
Cada comunidade precisa de registros rápidos e de fácil compreensão de sua mortalidade (da dos vitais), sem os quiais não è possivel haver base segura para o conhecimento e encontro de novas responsabilidades ao administrador sanitário (RAVENHOLT, 1962). 
4. PROPOSIÇOES PARA MUDANÇA 


\section{PROPOSIÇOES PARA MUDANÇA}

No Brasil, as principais instituições in teressadas na coleta, processamento, análise, publi cação e utilização dos dados quanto a recursos, atendimentos e morbidade em zoonoses, os Ministérios da Saúde e Agricultura e as Secretarias de Saúde e Agricultura, não mantêm, na maioria dos casos, mecanismos capazes de promover a integração entre os Setores de Saúde Humana e Animal, a um nível compa tível com o desenvolvimento eficaz do sistema de in formação, decisão e controle das zoonoses. O Programa Nacional de profilaxia da Raiva é um dos que visam essa integração (BRASIL, 1973). A Divisão Cen tro de Controle de zoonoses da Secretaria de Higie ne e Saúde da Prefeitura de são Paulo mantém essa integração a nivel municipal e da Grande São Paulo.

Há uma necessidade de se estabelecer mecanismos de integração entre os Setores de Saúde Hu mana e Animal para evitar duplicidade de ações, au sência de participação inter-ministerial e para se 
conséguir soma de esforços e recursos com reflexos na diminuição dos custos dos programas e na eficácia do sis.tema de informação, decisão e controle das zoonoses.

4.1. PROPOSIÇÃO $A$

A semelhança do Ministērio da Agricultura, onde há uma Divisão de Defesa Sanitāria Animal que cuida dos aspectos referentes à área de saúde animal, notadamente no tocante aos problemas de or dem econômica, também deverá existir uma Unidade de Saúde Pública Veterinária, no Ministērio da Saúde, que cuidará dos aspectos relacionados à saúde animal, com ênfase para a saúde pública.

A Unidade de Saúde Pública Veterinária te rá como principais funções e atividades:

I - promover a integração entre os setores correspondentes de saúde humana e saúde animal;

II - promover ações visando a agilização, bem cọ mo a integração, das unidades de estatisticas de saúde em zoonoses, a nível federal e estadual; 
III - promover a execução e executar, quando as sim, determinado, programas de controle das zoonoses;

IV - planejar e executar programas de treinamen- to de pessoal de nível médio e superior;

V - promover reuniões de estudos e debates sobre problemas de zoonoses;

VI - promover a divulgação de assuntos relacionados a zoonoses, na área de sua competência;

VII - elaborar projetos de pesquisa visanso o desenvolvimento mais eficaz dos programas de combate às zoonoses;

VIII - colaborar com as demais instituições em matéria de sua competência.

4.2. PROPOSIÇÃO B

Estimular a criação de um Centro Nacional de Controle de zoonoses, tendo um Conselho Consultivo ou Orientador, constituído por representantes dos organismos envolvidos na problemática, como Mi nistério da Agricultura, Ministērio da Saũde, Central de Medicamentos (CEME), OPAS/OMS, Fundação SESP, Fundação IBGE, Faculdades de Veterinária e de Medi. cina, Indūstrias Farmaucêuticas de produtos de uso 
humano e veterinārio e outros organismos.

o Centro Nacional de Controle de zoonoses terā como principais funções e atividades:

I - incrementar a criação de centros Estaduais de Controle de zoonoses integrando-os ao sis tema nacional;

II - agilizar os Centros de Controle de Zoonoses já existentes em alguns Estados, integrando-os ao sistema;

III - elaborar uma nomenclatura padrão para as zo onoses;

IV - padronizar e simplificar formulários com bạ se em dados mínimos;

V - elaborar normas e procedimentos;

VI - realizar treinamento de pessoal;

VII - sugerir a criação de mecanismos legais, quan do necessârios, para agilizar o processo de coleta de dados;

VIII - processar os dados que forem coletados a ni vel Estadual, possibilitando a geração de critērios de decisão para os órgãos governa mentais;

IX - gerar novas informações atravēs de sinteses da situação, compilações críticas, anālises, resenhas, etc. 
$X$ - esclarecer seu püblico especifico e público em geral, no que diz respeito à vigilância epidemiológica das zoonoses (pesquisa de no vas informações, situação atual das zoonoses existentes, etc.);

XI - promover a integração nacional dos diversos órgãos que se ocupam das estatísticas de sa ūde em zoonoses;

XII - facilitar o intercâmbio de informações entre os vários Estados da Federação e entre países;

XIII - servir de Laboratório de Diagrōstico de Referência Nacional.

A criação do Centro Nacional de Controle de zoonoses, para os fins especificos a que se pres ta, permitirá que os Centros Estaduais se desenvoI vam onde e quando forem necessārios, de uma forma espontânea, porēm uniforme.

Tais Centros só fornecerão os dados básî cos aos governos nas āreas respectivas, e não se $\underline{u}$ tilizarão dos dados para outros fins que não os do convênio.

Os Centros de Controle de zoonoses serão órgãos de assessoramento dos governos da União, dos 
-Estados, dos Municípios, dos Territórios e do Distrito Federal, para assuntos de sua competência.

Os Centros Estaduais poderão desenvolver as seguintes funções e atividades:

I - dar insumos para a atualização da nomenclatụ ra padrão de zoonoses e dos formulārios;

II - realizar inventārio, pesquisas e promover a integração dos recursos humanos e institucio nais de zoonoses em sua ärea, principalmente no tocante às estatisticas hospitalares, estatísticas ambulatoriais e a iniciativa particular;

III - determinar a prevalência das zoonoses em sua ārea;

IV - coordenar as ações de combate às zoonoses ser vindo como Centro de Treinamento para a padronização de normas, metas, e procedimentos dos vários municípios de sua ārea;

V - realizar atividades de diagnóstico das zoono ses;

VI - estabelfcer um mecanismo retro-alimentar para os produtores de dados bāsicos, de forma a acelerar o processo de desenvolvimento da vigilāncia epidemiológicá das zoonoses.

De acordo com as circunstâncias poderão ser estabelecidos Sub-Centros Fstaduais, em diver- 
sos pontos do Estado, a fim de facilitar o fluxo de informações, bem como a investigação. 
5. DISCUSSÃO 


\section{DISCUSSR̃}

Os meios e mētodos postos à disposição pa ra a prevenção, controle e erradicação das doenças transmissiveis ainda não têm sido convenientemente absorvidos ou assimilados pela maioria dos países latino-americanos (OPAS, 1972). Talvez a não utilização mais eficiente desses métodos seja devido a problemas de ordem cultural, operativa, econômica e social (OPAS, 1974).

Os organismos nacionais e internacionais que se encarregam da vigilância epidemiológica têm dificuldades para reconhecer e analisar oportunamente as características epidemiológicas das doenças e as causas que intervêm nesse processo, na maio ria dos paises das Américas (OPAS, 1974; ROMERO E VALVERDE, 1975). Para suprir a deficiência total de dados clínicos em Veterinária, os Estados Unidos da Amērica elaboraram uma nomenclatura padrão de doenças e operações animais (SNVDO), eficiente para a situação norte-americana (TJALMA, 1964), po- 
rēm, adaptado sem sucesso às condições uruguaias (NEWSAN, 1976), às condições mexicanas (FERNANDEZ, 1976) e às condições ínglesas (DAVIES, 1976).

A ausência completa de informações ou 0 fornecimento de informações incompletas ou'vicia das, não permitem ao administrador sanitário se utilizar dessas informações, a um nível confiável, para tomar as suas decisões (OPAS, 1974; LAURENTI, 1971). No periodo de 1969 a 1973, enquanto que o órgão oficial encarregado da coleta e registro de dados em saúde informava não haver um só caso de Cisticercose em humanos, em quatro grandes hospitais do município de São Paulo, SILVEIRA (1974) en controu 117 casos. Hä, pois, uma tendência à não notificação de casos de zoonoses por parte de alguns hospitais, no Estado de São Paulo. Levando-se em consideração que o Estado de são Paulo é o mais bem dotado de recursos de ordem econômica e operativa do Brasil, podemos afirmar, com possivel erro mínimo, que tal situação, de ausência quase total de notificações, é idêntica para todo o Brasil.

Hâ uma crise conceitual sobre a real uti lização das estatîsticas de saúde. O desconhecimento generalizado da importância de informar, do 
que informar e de bem informar gera consequências desastrosas que contribuem para a estagnação de mui tos dos programas sanitários (ASTUdlLLO, 1972).

Analisando-se alguns dos programas de sa úde animal até o presente, vê-se que há uma tendên cia para se registrar mais atendimentos que morbidade (ASTUDILLO, 1972). O objetivo sanitário das campanhas de saúde animal tende a ser superado peIo interesse burocrático, a menos que se reverta ao seu objetivo primārio. Há mais informações de cunho administrativo sem valor sanitário. Assim, o administrador, em geral, se interessa mais pelo nב mero de atividades realizadas do que a real eficiência dessas atividades. Não queremos dizer que este tipo de avaliação não seja importante, mas apenas ressaltar a importância que avaliações do ti po meramente burocrático vem assumindo em detrimen to das avaliações essencialmente sanitárias nos programas de saúde.

As informações deficientes, a duplicidade de ações e a consequlente falta de integração en tre os diversos órgãos públicos que cuidam do problema, incorre na ineficiēncia dosserviços de vigi lância epidemiológica do Brasil (LEMOS, 1973; BRA 
SIL, 1971). Deve-se imprimir ao setor uma centralização normativa e uma descentralização executiva (LEMOS, 1973). Com as proposições $A \in B$, apresentadas no item 4, visamos reduzir esses inconvenien tes promovendo a integração dos setores de saūde Hu mana e Animal. Tanto a Unidade de Śaúde pública Ve terināria (proposição A) como o Centro Nacional de zoonoses e os Centros Estaduais (próposição B), são alternativas que podem ser tomadas em conjunto ou separadamente, sendo desejāvel que ambas sejam tomadas.

A integração dos Setores de Saúde Humana e Animal vem simplificar e facilitar a organização e o financiamento em comum das campanhas de contro le pertinentes, contribuindo para melhorar os serviços e promover a assistência mútua em trabalhos de investigação epidemiológica e de laboratórios (LEMOS, 1973; FSESP, 1976). Supõe o desenvolvi mento simultâneo e paralelo de todas as atividades dos órgãos afins, eliminando-se duplicidade de ações com otimização do dinamismo e rapidez de atua ção (FSESP, 1976).

A criação de uma Unidade de Saũde Pūblica Veterināria, como parte integrante do Ministē- 
rio da saúde, tem sido inestimável para a integra ção entre os Setores de Saúde Humana e Animal, nos países que jā adotaram essa medida. A Unidade de Saūde püblica Veterināria vem prover um "endereço" ou um "ponto focal" para as atividades de interesse comum entre as medicinas humana e veterināria, favorecendo o fluxo de informações entre ambas as ciências (FSESP, 1976).

A criação do Centro Nacional de Controle de Zoonoses e dos Centros Estaduais de Controle de zoonoses vem imprimir um nível de aceleração compa tível com a rapidez de atuação, dando maior especi ficidade ao controle das zoonoses. Como Laboratório de Diagnóstico Estadual e centro de coleta de dados, permitirā que condições semelhantes sejam es pecificadas e codificadas em termos semelhantes pa ra assegurar a comparabilidade e categorização ana lítica (TJALMA, 1964). 
6. CONCLUSOES 


\section{CONCLUSÕES}

1. Hà uma ausência, quase que total, dè notificações de casos humanos de zoonoses no Brasil.

2. Há uma tendência generalizada de së registrar mais informações de cunho administrativo-buro crático que de cunho administrativo-sanitārio, nas campanhas sanitārias do Brasil.

3. São vārios os organismos públicos que cuidam de um modo ou de outro de estatisticas de saúde re lacionadas às zoonoses.

4. Há duplicidade de ações entre os organismos interessados no combate às zoonoses.

5. Devido a uma série de fatores de ordem econômica, social, cultural e operativa, o sistema de informação, decisão e controle das zoonoses no Brasil, se encontra deficiente. 
6. Há necessidade de se promover a integração dos Setores de Saúde Humana e Animal para se obter um nível de aceleração do sistema de informação, decisão e controle das zoonoses compatível com a realidade do país.

7. Para promover a integração dos setores de Saüde Humana e Saúde Animal propõe-se: a criação de u ma Unidade de Saúde pública Veterinária, como par te integrante do Ministério da Saúde e/ou a cria ção de um Centro Nacional de Controle de Zoonoses e de Centros Estaduais de Controle de Zoono ses. 


\section{ABSTRACTS}

After to define statistics, bioestatistics, epidemiology, epidemiology surveillance and systems, the autor analises the information, decision and control system of transmisibles diseases and zoonoses to health statistics in zoonoses from Brazil.

The autor concludes that health statistics in zoonoses from Brazil are very poor like the major latin americans countries. The health administrator do not have confiable statistics in suficient quality or quantity, in order to take rapide, eficient and real decisions.

The autor proposes the creation of a Veterinary Public Health Branch as a essential part of the Health Ministry. The autor also proposes the creation of a National Zoonoses Control Center and Zoonoses Control Centers in the states of Brazil, with wide participation of public organisms and private iniciative. All of them have the prior fi nality to get better integration of Human and Animal Health sectores and to improve the zoonoses in formation, decision and control system in Brazil. 
REFERENCIAS BIBLIOGRAFICAS 


\section{REFERENCIAS BIBLIOGRAFICAS}

ASTUDILLO, V. - Proyecto de desarrollo de sistemas de notificación y de registro dedatos sobre las enfermidades de los animales. IN: REUNION INTERAMERICANA SOBRE EL CONTROL DE LA FIEBRE AFTO SA E OTRAS ZOONOSES, 4a., Lima, 1971. Washington, D.C., Organización Panamericana de la Salud, 1972. p. 63-96 (Publ. cient. 236)

BERQUO, E. et al. - Estatística Vital. São Paulo, Faculdade de Saüde Püblica, USP, 1971 (apostila do) .

BRASIL. Leis, decretos, etc. Decreto n: 24.548 , de $03 / 07 / 1934$.

BRASIL. Leis, decretos, etc. Decreto-Lei n? 200 , de $21 / 02 / 1967$.

BRASIL. Leis, decretos, etc. Lei n: 6.229, de $17 / 07 / 1975$ (a).

BRASIL. Leis, decretos, etc. Lei n? 6.259, de $30 / 10 / 1975$ (b).

BRASIL. Ministêrio da Saúde. Programa Nacional de Profilaxia da Raiva. 1973.

BRASIL. SUDESUL. Documento final do Encontro regional sobre estatísticas de saüde. Porto Alegre, 1971. 
BURQUETE OSORIO, J.M. - Un servicio de vigilancia epidemiologica nacional. Su importancia para el enfoque científico de las atividades sanitárias. Salud public mex, 14:234-7, mar./apr., 1972.

CAJAS, R. - Jerarquia de sistemas. Jaboticabal, jun., 1976, 3p. (datilografado).

CARVALHO, H.M. de - Uma abordagem operacional da teoria de sistema aplicada à producão agrícola. Jaboticabal, jun., 1976. 58 p. (datilografa do) .

DEAK, J.G. - Sistema estatístico em saüde animal. Boletim Informativo do GECOFA - SP, (4):21-38, 1973.

EHLERS, R.F. - A estatistica e o planejamento. IN: BRASIL, SUDESUL, Documento final, Encontro regional sobre estatisticas de saüde. Porto Alegre, 1971, p. 1-18.

ELKIN, 1.1. - A course of epidemiology. 0xford, Pergamon Press, 1961. p. 3-75.

FOSSAERT, H. et al. - Sistemas de vigilância epide miolögica. Bol. Ofic. sanit.panam., 76:512-28, jun., 1974.

FUNDAÇÃO IBGE - Consideracões sucintas sobre ativi dades do CEBEA. Rio de Janeiro, Centro Brasileiro de Estatísticas Agropecuārias, 1976. 
FUNDAÇAO SESP, Rio de Janei ro - Contribuição do mé dico-veterinärio nas atividades de saüde pública-Parte 1. Bol.Epid., 8(1):1-12, 1976.

HORWITZ, A. - Discurso del Director de la oficina Sanitária Panamericana. IN: REUNION INTERAMERICANA SOBRE EL CONTROL DE LA FIEBRE AFTOSA Y TRAS ZOONOSES.. 2a., Rio de Janeiro, 1969. Washington, D.C., Organización Panamericana de la Salud, 1970. (Publ. cient., 196).

KLOETZEL, K. - As bases da medicina preventiva. São Paulo, EDART, 1973.

LAURENTI, R. - Situação atual do sistema de informação de estatísticas de saúde na Região sul. IN: BRASIL, SUDESUL - Dorumento final: Encontro regional sobre estatísticas de saúde. Tema 1. Porto Alegre, 1971.

LAURENTI, R. et al. - Alguns aspectos epidemiológi cos da mortalidade por acidentes de veículos a motor na cidade de São Paulo. Rev. Saūde pübl., São Paulo, 6:329-34, 1972 .

LAURENTI, R: - 0 problema das doenças crónicas e degenerativas e dos acidentes nas áreas urbanizadas da Anërica Latina. Rev. Saüde pübl., São Paulo, 9:239-48, 1975 .

LEMOS, M.M. - Apresentação do Programa Nacional de Profilaxia da Raiva. IN: BRASIL. Ministērioda Saúde. Programa Nacional de Profilaxia da Rai va, 1973 . 
MACIEL, G.A. \& PAIM, G.V. - Os dados nosográficos obtidos através do matadouro e a sua importância para a saūde püblica. Arch.Fac. Hig. S.P., São Paulo, 20:241-49, 1966.

MACMAHON, B. et al. Métodos de epidemiologia. México, La Prensa Mexicana, 1965.

MARCHEVSKI, N. - Información del servicio de campo de sanidad animal: propuesta de cambio. Zoonosis, $17(1-2): 45-56,1974$.

OLIVEIRA, Q.C. de - Administração hospitalar: aspectos epidemiológicos do prontuärio do Hospital das Clínicas Veterinärias da Universidade Fe deral de Santa Maria, no período de $1970-1974$ através de processamento eletrónico de dados. Santa Maria, 1975 (Tese de Mestrado - mimeografado).

ORGANIZAÇAOO MUNDIAL DA SAODE. Comitê mixto OMS/FAO de Expertos in Zoonosis. Informe: 3\%, Ginebra, 1967. (Org. Mund. Salud, Ser. Inf. técn. 378).

ORGANIZAÇAO MUNDIAL DA SADDE. Veterināria de Salud Pública: exame del programa de la OMS - 1: Cronica de la OMS, 28:111-21, 1974 .

ORGANIZAÇÃO PAN-AMERICANA DA SAODE. Métodos para mejorar las estatisticas vitales e de salud: Dis cusiones Técnicas. REUNION DEL CONCEJO DIRECTI VO DE LA OPS. Documento de trabajo: 3\%, Washington, D.C. 1966. 
ORGANIZAÇAOO PANAMERICANA DA SAODE - Proposiciones de cambio y estratégias de salud para la decada 1971-1980. REUNION ESPECIAL DE MINISTROS DE SE LUD DE LAS AMERICAS, 3a., Documento básico de referéncias. Washington, D.C., 1972.

ORGANIZAÇAO PAN-AMERICANA DA SAODE - Profillaxia das doenças transmissiveis. Washington, D.C., Publ. cient. $(268), 1973$.

ORGANIZAÇÃO PAN-AMERICANA DA SAODE - Sistemas de vigilância epidemiológica de las enfermidades trans misibles y zoonosis. Publ. cient. (288), 1974.

PETERS, J.A. - Veterinary clinical data: an epidemiologic research resource. Amer. J. Publ. Health, 56:1837-9, Nov., 1966.

RASKA, K. apud FOSSAERT, H. et al. - Sistemas de vigilância epidemiológica. Bol. Ofic. sanit. panam., 76:512-28, jun., 1974.

RAVENHOLT, D.T. - Historical epidemiology and grid analysis of epidemiologic data. Am.J. publ. Health, 52:776-90, May, 1962 .

ROMERo, A. E VALVERDE, E. - Estabelecimiento de un sistema integral de vigilância epidemiológica. Bol. Ofic. sanit., 78:501-518, 1975.

SÃo PAULO (Estado) - Leis, decretos, etc. apud IARIA, S.T. - Zoonoses e geografía médica. IN: LACAZ, C. da et al. - Introdução à geografia mé dica do Brasil. São Paulo, E. Blucher/EdUSP 1972, pp. 241-58. 
SÃo PAULO (Estado) - Leis, decretos, etc. Decreto n? 2.862 , de $21 / 11 / 1973$.

SÃo paUlo (Município) - Leis, decrétos, etc. Decre to $n$ : 7. 835 , de $12 / 12 / 1968$.

SÃo PAULO (Município) - Leis, decretos., etc. Decre to $n: 9.072$, de $27 / 10 / 1970$.

SĂo PAULO (Município) - Leis, decretos, etc. Decre to $n$ : 9.850 , de $17 / 02 / 1972$.

SÃo pAULO (Município) - Leis, decretos, etic: Decre to n? 10.435 , de $03 / 04 / 1973$.

SĂo PAULO (Município) - Leis, decretos, etc. Lei n: 8.108 , de $02 / 09 / 1974$.

SÃo PAULO (Município) - Leis, decretos, etc. Decre to $n$ : 11.632 , de $13 / 12 / 1974$.

SCHWABE, C.W. - Medicina veterināria y salud pública, Mëxico, Editorial Novaro, 1968..

SILVEIRA, A.P. - Casos humanos de zoonoses no Esta dos de São paulo no periodo de 1969-1973. São Paulo, 1974.. (Trabalho apresentado à Disciplina Saūde Püblica Veterināria, FSP/USP).

SoUNIS, E. - Bio-estatística. São Paulo, McGraw Hill do Brasil, 1971, P. 11-41. 
TJALMAA, R.A. et al. - Clinical records systems and data retrieval function in Veterinary Medicine: a proposal for systemic data programming. J.A. V.M.A.; 145(12):1189-97, Dic. 1964 . 
A NEXOS 
FICHA INDIVIDUAL DE TRATAMENTO ANTI-RABICO HUMANO

SECRETARI/ DE SAÚDE DO ESTADO DE

ESTAOELECMENTO

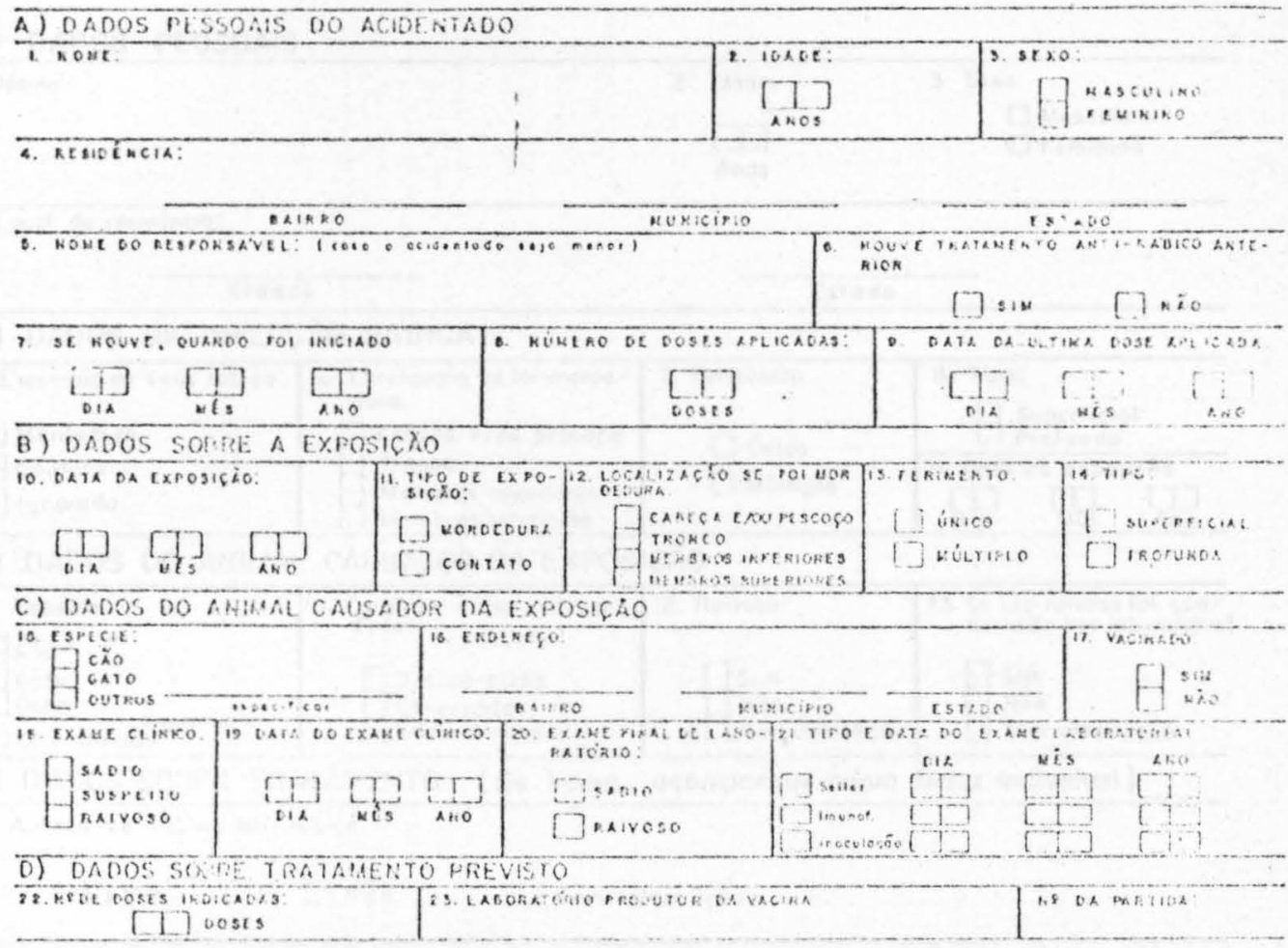

E) DATA DAS APLICACÒES

\begin{tabular}{|l|l|l|l|l|l|l|l|l|l|l|l|l|l|l|l|l|}
\hline & 19 & 20 & 30 & 40 & 50 & 69 & 79 & 89 & 99 & 100 & $11^{\circ}$ & 120 & 139 & 140 & 81 \\
\hline MES & & & & & & & & & & & & & & & & \\
\hline DIA & & & & & & & & & & & & & & & & \\
\hline
\end{tabular}

* $R_{1}-19$ cose de Reforgo

* $* R_{2} * 2^{0}$ dose de Reforço

F) UBSERVACÕES:

A- Registror se foi utilizodo soro, quontidodo, titulo e Loborotóno f odutor.

B-So houva interrupsio do Irolomento, indicor o m tivo.

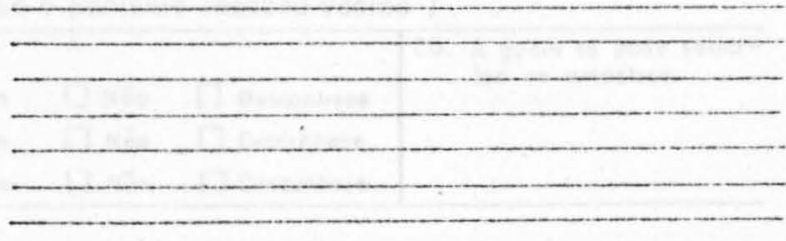

Assinatura

ER.VE.P.1

ANEXO I 
FICHA DE INFORMACÃO EPIDEMIOLÓGICA DE CASOS DE RAIVA HUMANA

A) DADOS PESSOAIS

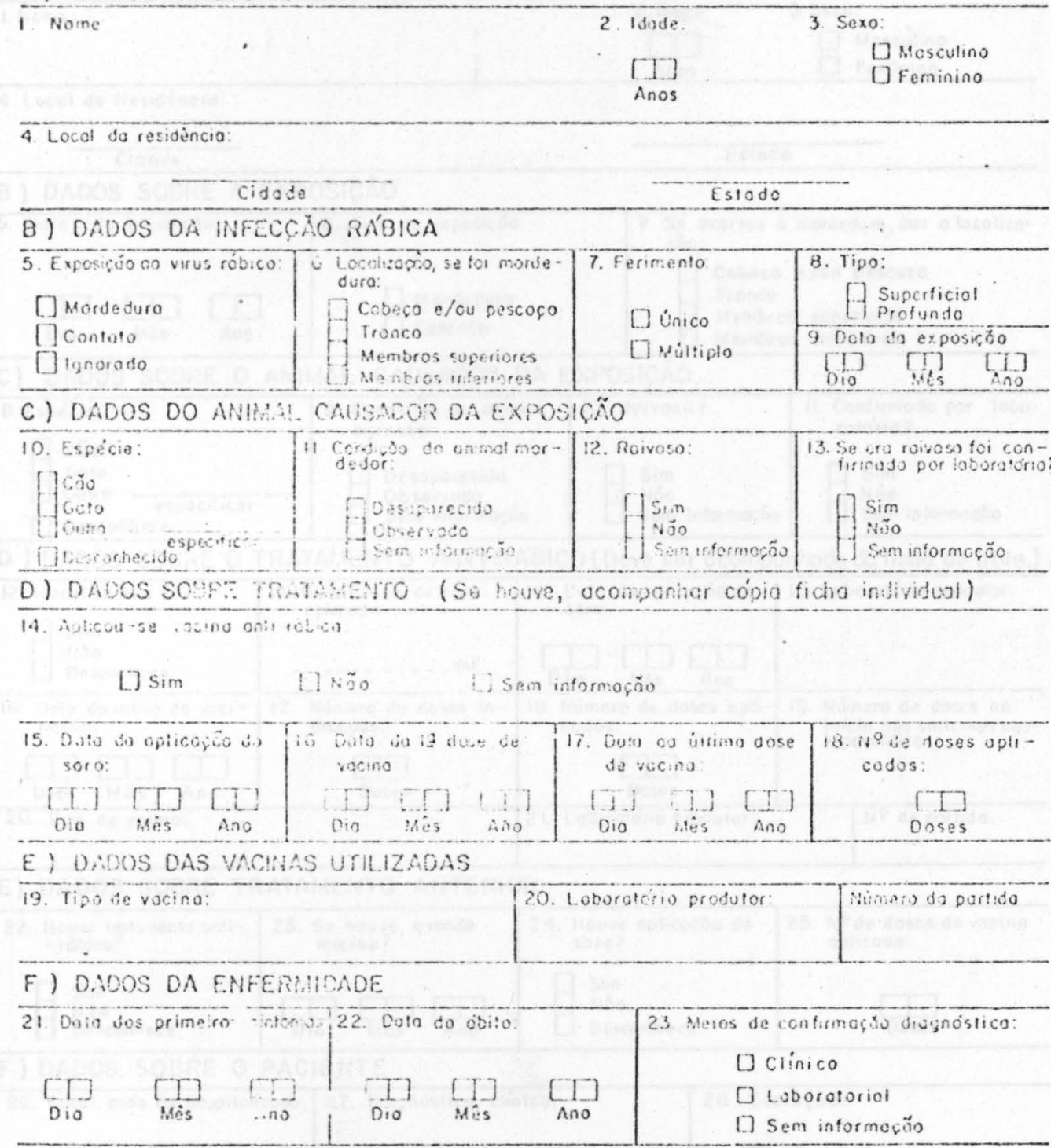

G) OADOS PAFA INVESTIGACÁAO (SE o paciente recoteu vacina)

\begin{tabular}{|c|c|c|c|c|}
\hline 24. Existem amostros disponlveis de: & & & & 25. A quom so pode solici- \\
\hline o) Vacino utilizoda? & $\square \operatorname{sim}$ & [ Näo & ПDescosheco & \\
\hline b) LRC do pociente? & [] $\operatorname{sim}$ & [] Nöo & [] Deeconhece & \\
\hline c) Soro sannuíneo do fucrente? & [] St: & {[] [i } & 1.] Cescuntece & \\
\hline
\end{tabular}

H) DADOS DO MFORMANTE

\begin{tabular}{l} 
Nome: \\
\hline Corgo \\
\hline Observoctás:
\end{tabular}

BR.VEP.2

Assinoturo 
FICHA DE INFORMAČ̃̃O EPIDEMIOLÓGICA DE

COMPLICACOES NEUROPARALITICAS HUMANAS ASSOCIADAS COM

A VACINACÄO ANTI-RÁBICA

A) DADOS PESSOAIS

\begin{tabular}{lccc}
\hline I. Nome: & 2.10 ade: & 3. Sexo: \\
& $\vdots$ & $\square T$ & $\square$ Mosculino \\
& 1 & $\square$ Anos & $\square$ Feminino \\
\hline
\end{tabular}

4. Locol de Residéncia:

\begin{tabular}{|c|c|c|}
\hline Cidade & & Eslodo \\
\hline DADOS SOBRE A & $\operatorname{Sic} \hat{\circ}$ & \\
\hline 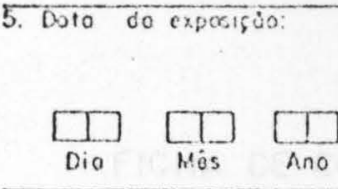 & $\begin{array}{l}\text { 6. Tipo de expostcóo } \\
\square \text { Mordeduro } \\
\square \text { Contato }\end{array}$ & $\begin{array}{l}\text { 7. Se ocorreu a mordeduro, dar a locoliza- } \\
\text { cố: } \\
\text { A Cobeco e /ou pescoco } \\
\text { Tronco } \\
\text { Membros superiores } \\
\text { Membros inferiores }\end{array}$ \\
\hline
\end{tabular}

C) DADOS SODRE O ANIMAL CAUSADOR DA EXPOSIÇÄO

\begin{tabular}{|c|c|c|c|}
\hline $\begin{array}{l}\text { 8. Espécie: } \\
\text { [] Cõo }\end{array}$ & $\begin{array}{l}\text { 9. Condif̧o do onimal } \\
\text { ogtessor: }\end{array}$ & 10. Roiroso? & $\begin{array}{l}\text { 11. Canfirmodo por labo- } \\
\text { ratório? }\end{array}$ \\
\hline Goto & Desaporecido & Sim & 口 $\mathrm{si}$ \\
\hline $\begin{array}{l}\text { 1] Outro especificor } \\
\square \text { Desconhece }\end{array}$ & 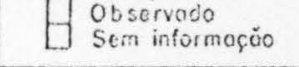 & H. Nóo $\mathrm{Sem}$ infornocio & H Nóo Sem informaçrio \\
\hline
\end{tabular}

D) DADOS SOBRE O TRATAMENTO ANTI-RÁBICO (Deve ser ocomponhado do ficho do trobo.)

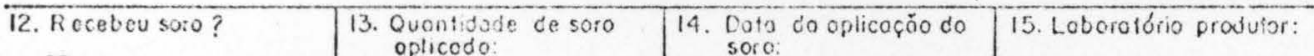

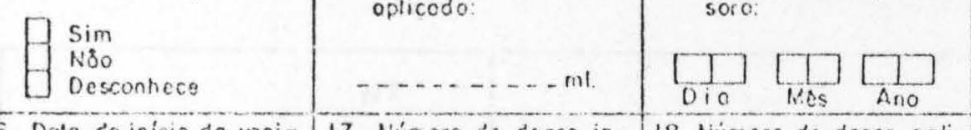

16. Doto do início do vaci- 17. Número de duses in- 18. Número do doses apli- 19. Número de doces ao

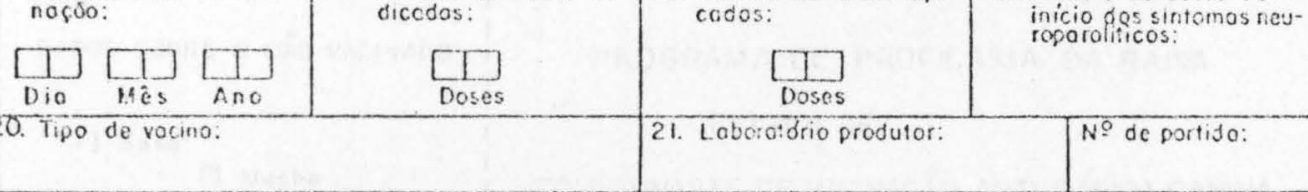

E) DADOS SOBRE TRATAMENTO ANTERIOR

\begin{tabular}{|c|c|c|c|c|}
\hline $\begin{array}{l}\text { 22. Houw frofoment anti- } \\
\text { - robico? } \\
\text { G } \begin{array}{l}\text { Sim } \\
\text { Nobo } \\
\text { Desconhece }\end{array}\end{array}$ & $\begin{array}{l}\text { 23. Se houve, quando } \\
\text { iniciou? }\end{array}$ & $\begin{array}{l}\text { 24. Houve oplicos } \\
\text { soto? } \\
\text { G } \begin{array}{l}\text { Sim } \\
\text { NSo } \\
\text { Desconhece }\end{array}\end{array}$ & ťo de & $\begin{array}{l}\text { 25. No de doses de vocina } \\
\text { oplicoda: }\end{array}$ \\
\hline \multicolumn{5}{|c|}{ F) DADOS. SOBRE O PACIEMTE } \\
\hline 26. Local onde foi hospital & 2000: 27. Dicgnústico & hico: & 28. $\begin{array}{r}\square \\
\square \\
\square\end{array}$ & $\begin{array}{l}\text { luçäo: } \\
\text { Melhorou } \\
\text { Sequelos } \\
\text { Foleceu }\end{array}$ \\
\hline
\end{tabular}

29. So foleceu, fol fcito outópsi- 30 . Se houve outópsio dor um resumo dos dodos principois:

$\square \sin \square \times \gamma_{0}$

G) DADOS DO INFORMANTE

\begin{tabular}{l|l|l|}
\hline Home: & Servico de soode: & Doto: \\
\hline Corgo: & & \\
\hline
\end{tabular}

Observocsos:

BR.VEP.3

Assinolura 
MOOELO - I

FICHA DE COMPROVANTE DE VACINACÃ́O AMTI-RÁBICA CANINA

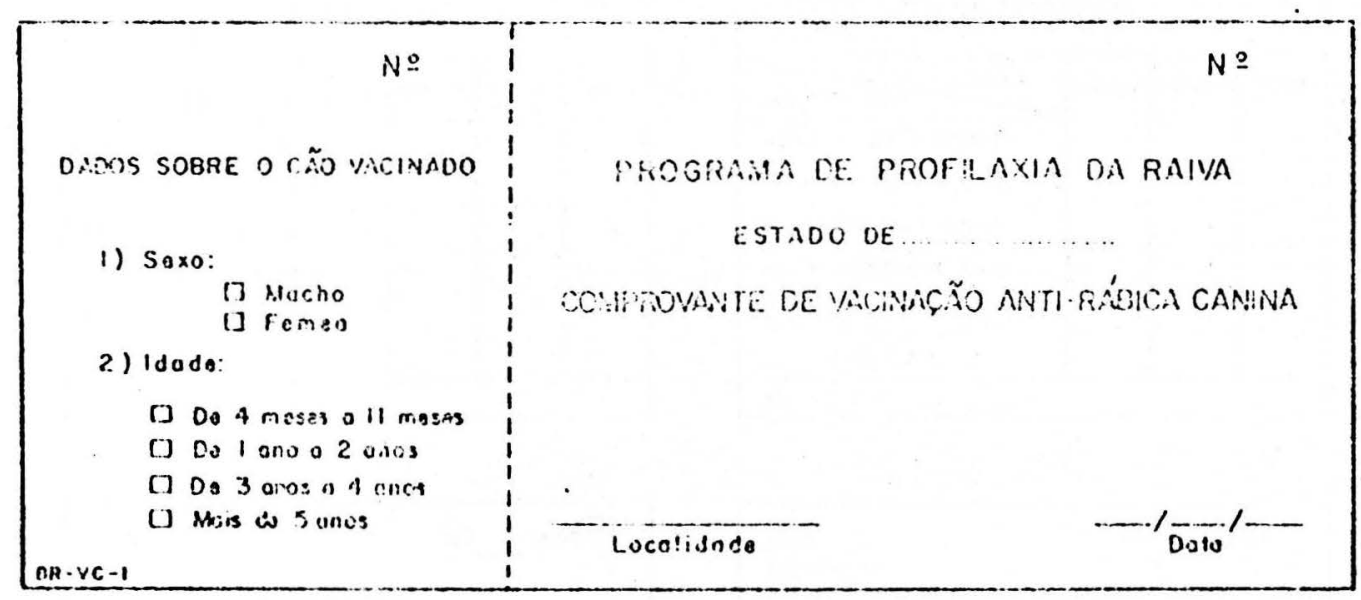

ANEXO IV 
MODELO- 2

FICHA RESIDENCIAL PARA INQUÉRITO DA
POPUIACGÄO CANINA

i ESTADO.

LOCALIDADE:

\begin{tabular}{|c|c|c|c|}
\hline \multicolumn{2}{|c|}{ 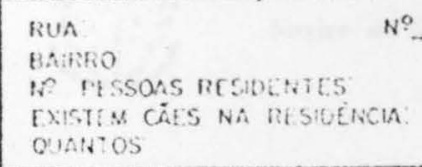 } & \multicolumn{2}{|c|}{$\operatorname{sik}[] \times \operatorname{se}[]$} \\
\hline towe to $2005 \times 0$ & nero & $F E A E A$ & TOIAL. \\
\hline \multicolumn{4}{|l|}{ NEvonts EL A MiSES } \\
\hline \multicolumn{4}{|l|}{ OE A MTSES A UH MESES } \\
\hline \multicolumn{4}{|l|}{ OE I ANO A 2 ANOS } \\
\hline \multicolumn{4}{|l|}{ DE 3 ANOS 4 A AMOS } \\
\hline \multicolumn{4}{|l|}{ MALRES DE 5 ANOS } \\
\hline$T O T A \mathrm{~L}$ & & & \\
\hline$A R-V C-?$ & & & \\
\hline
\end{tabular}

\begin{tabular}{|c|c|c|c|}
\hline 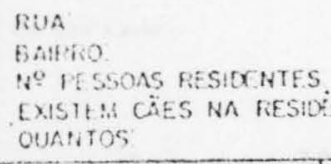 & NOP & $\triangle A P$ & D $n x_{0}$ \\
\hline IDACE OC CAO SEXO & natan & FENEA & TOTAL. \\
\hline MEROQES OE 4 HESES & & . & \\
\hline OE \& VISES A II MESES & & & \\
\hline OE I ANO A 2 ANOS & & & \\
\hline DE. 3 ANCS A 4 ANOS & & & \\
\hline NAIOZTS UE 5 ANOS & & & \\
\hline TOTAL & & & \\
\hline
\end{tabular}

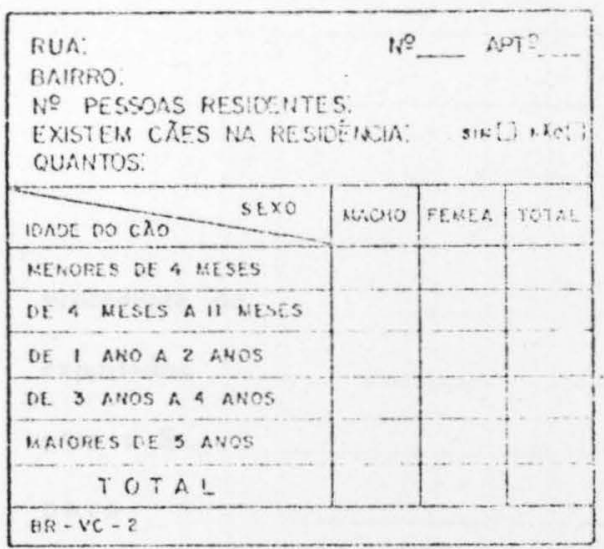

\begin{tabular}{|c|c|c|c|}
\hline \multicolumn{2}{|c|}{ 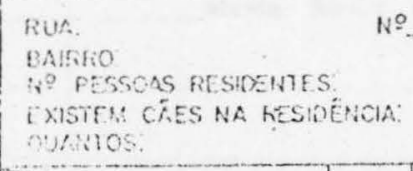 } & \multicolumn{2}{|c|}{$\begin{array}{l}\text { APT: } \\
\sin [] \operatorname{Ri}[]\end{array}$} \\
\hline ICAOE $120.2 \quad$ SEXO & H:AO:O & FEMEA & TORAL \\
\hline MELOEES OE 4 VESES & & & \\
\hline oc \& rirses a 11 veses & & & \\
\hline DE I ANO A 2 ANOS & & & \\
\hline Of 3 ANOS A 4 ANos & & & \\
\hline Whines $\mathrm{m}$ a Allos & & & \\
\hline TOTAL & & & \\
\hline $8 n-V C-2$ & & & \\
\hline
\end{tabular}

\begin{tabular}{|c|c|c|c|}
\hline \multicolumn{2}{|c|}{$\begin{array}{l}\text { RUA: } \\
\text { BAIRIRO: } \\
\text { NO PESSOAS RESIDERTES } \\
\text { EXISTES CÃES NA RESIOLIKLA: } \\
\text { OUANTOS: }\end{array}$} & \multicolumn{2}{|c|}{$\begin{array}{l}\text { APTO } \\
\sin 0 \times \text { Nio } C\end{array}$} \\
\hline TOATE DOCAO SEXO & NACNON & FEMEA & TOTAL \\
\hline UEMCAES OC \& MESES & & & \\
\hline DE $A$ HECSES A $\|$ VESES & & & \\
\hline DE I ANOA 2 ANOS & & & \\
\hline OE 3 ANOS A 4 ANOS & & & \\
\hline MAIOAES DE 5 ANOS & & & \\
\hline TOTAL. & & & \\
\hline$B a-v G-2$ & & & \\
\hline
\end{tabular}

\begin{tabular}{|c|c|c|c|}
\hline \multicolumn{2}{|c|}{$\begin{array}{l}\text { KUA: } \\
\text { BAIKRO } \\
\text { NO PESSOAS FESIOENTES } \\
\text { EXISTEM CÄES NA RESIDENCIA: } \\
\text { OUANTOS: }\end{array}$} & \multicolumn{2}{|c|}{$\operatorname{APT}:$} \\
\hline IDADE DOCAO SEXO & MACITO & FEREA & TOTAL \\
\hline NENORES CE 4 MESES & & & \\
\hline OE \& MEESES A $\|$ WESES & & & \\
\hline DE I AHO A 2 ANOS & & & \\
\hline OE 3 ANOS A 4 ANOS & & & \\
\hline NAIONES OE 5 ANOS & & & \\
\hline TOTAL & & & \\
\hline
\end{tabular}




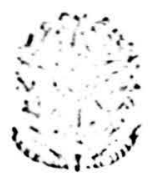

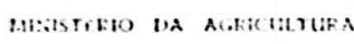

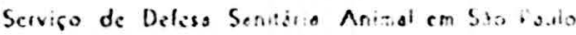

StRIf - "C"

Vis

CERTIFICADO de Inspecào Saniária Animel

O abaixo assinado

por determinasio regulamentar $e$ a requisicato do Se.

atesta have inspecinatio

procediste di

animai- importadus at

cxportados

parat o Sr.

para

Estands oz animais com aparéncia de perfeita saude, sou de parcer que pojem ter de live tránsito.

de de 19

O feru-cimento di te certiticado e inteiratacate GRitis.

vititu POK ................. Mas. 
ricls inserenica

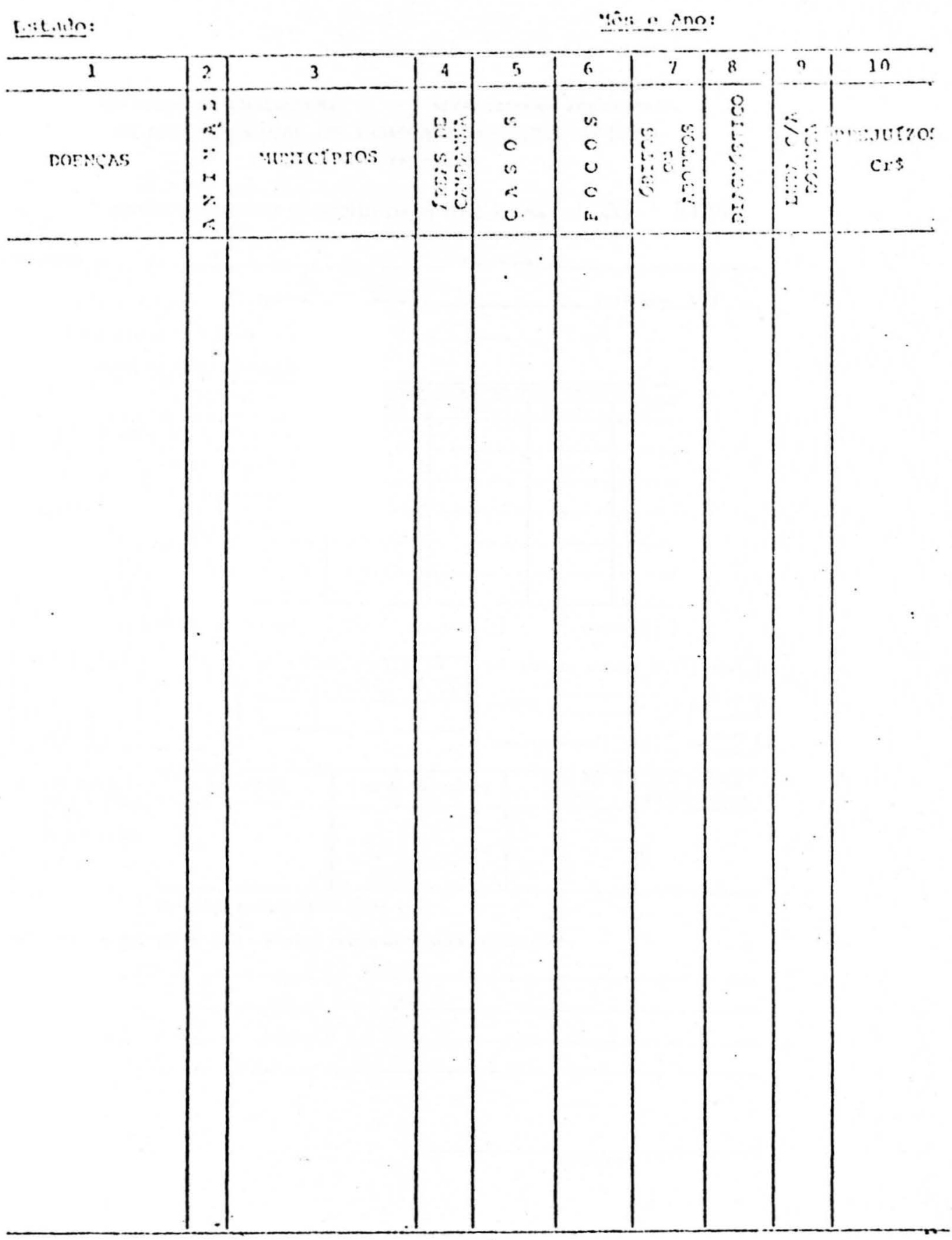

n"senuscris:

(Incal $=$ diata) 
MIRISIEHIO DA AGHLULYURA SECRETARIA OA AGRICULTURA

PLANO NACIONAL DE CONB3ATE A FEBRE AFTOSA

cecora - sAO raULO

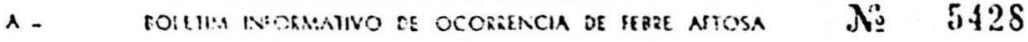

Propicietsro

Presiestode

hos

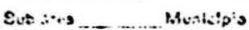

Coxce:eess ....... 1

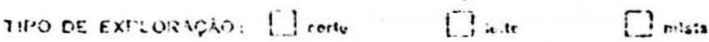

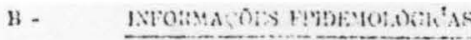

\begin{tabular}{|c|c|c|c|c|c|}
\hline & \multirow{2}{*}{ ESPRcit: } & \multirow{2}{*}{ 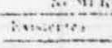 } & \multirow{2}{*}{$\ldots \ldots$} & & \\
\hline & & & & \multirow{2}{*}{ Inersts } & AN: \\
\hline \multirow[t]{2}{*}{ novis } & 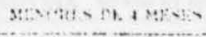 & & & & \\
\hline & DE A NES:SA A ASA & & & & \\
\hline \multirow[t]{2}{*}{ ". } & 14. 1 ANO + 2 ANOSE & & & & \\
\hline & 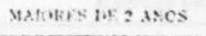 & & & & \\
\hline \multicolumn{2}{|l|}{ Stiki } & & & & \\
\hline OITIAS & & & & & \\
\hline
\end{tabular}

C -

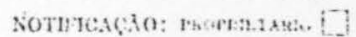

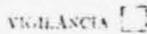

moctmos [?

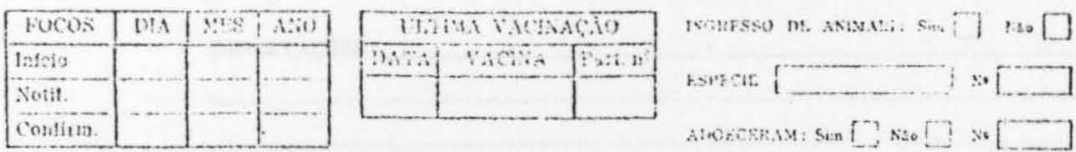

D - Col.HसT: DE M:ATEMAL

PAlid

Tiplicescio

\begin{tabular}{|c|c|c|c|}
\hline Frescess $\mathrm{N}$ & Jipo de Mfortial (") & $\begin{array}{l}\text { Tatn da } \\
\text { Collecits }\end{array}$ & $\begin{array}{l}\text { lusta da liem. } \\
\text { 20 inboratgrio }\end{array}$ \\
\hline & & & \\
\hline & & & \\
\hline
\end{tabular}

(v) Hagux, genziva, casea, there, cle.

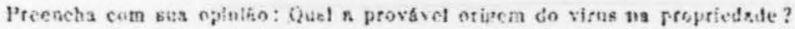

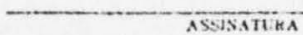

IV V. CECGHA

ANEXO VIII 
MINISTERIO DA AGRICULTURA SECRETARIA DA ACHICULTURA

PLANO Nacional de coimbate a fEibire aftosa

CecorA - SA P PALLOS

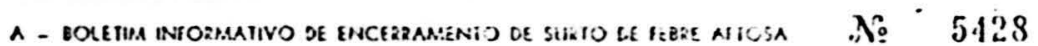

Preprielurio

Properetse.

Ano

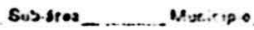

Cocrdersts:

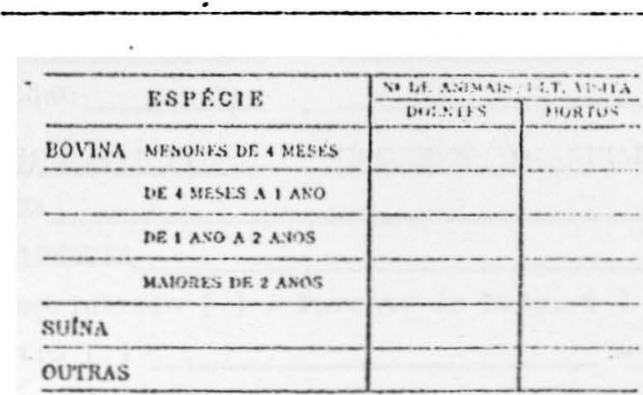

\begin{tabular}{|c|c|c|}
\hline & nis & MES/ ANo \\
\hline 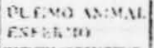 & & \\
\hline 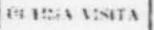 & & \\
\hline $\begin{array}{l}\text { ox: } 1 \text { ind wise } \\
\text { Aetstiot: }\end{array}$ & & \\
\hline
\end{tabular}

OBSERVAÇŌES :

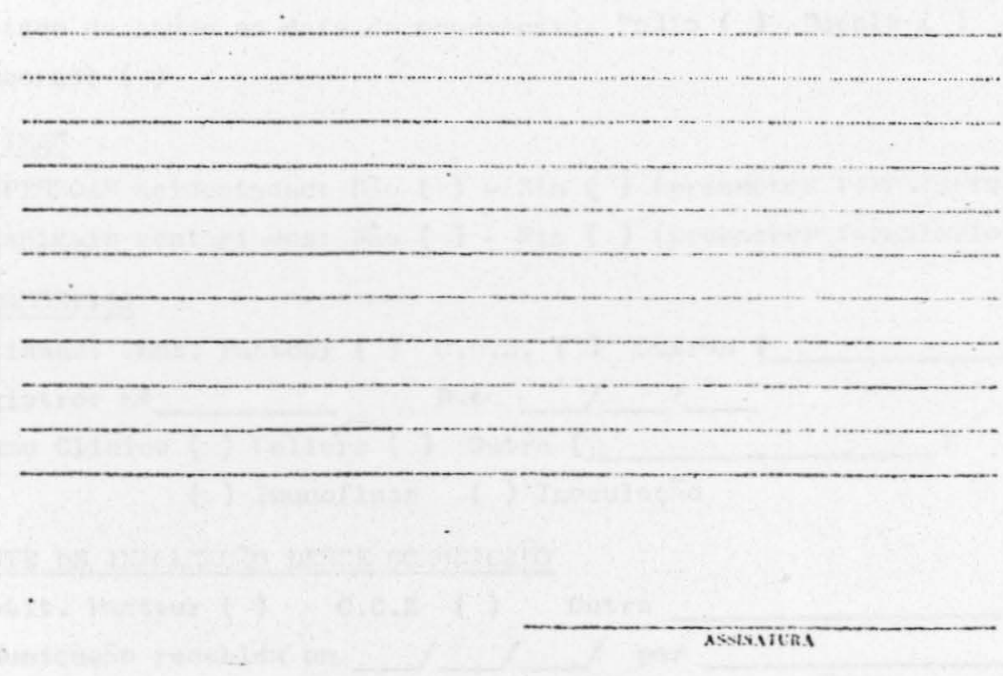

a vencors

\section{ANEXO IX}



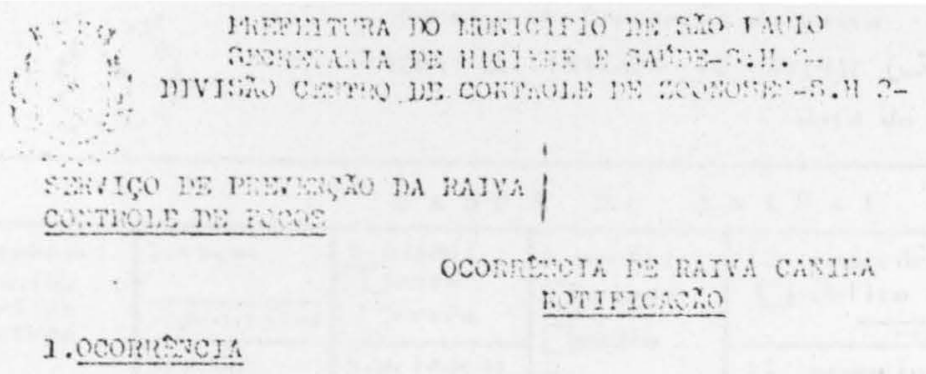

\subsection{0orrovers}

10CAL:

BATHito: ili

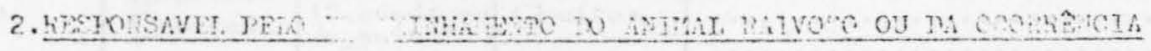
Honiv: RESIIMUKTA

- Proprietsuio ( ) - Parente do Prop. ( ) - Vizinho do Prop. ( ) -outro ( ) - Icrorido ( ).

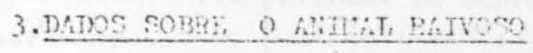

-Especie: Sero: Ziatho ( ) Funea ( )

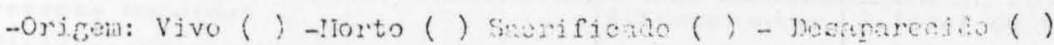
-Estedo de snále na data de ocomocrin: Cadio ( ) Docnie ( ) IEnorado ( )

4. VIJIMU:

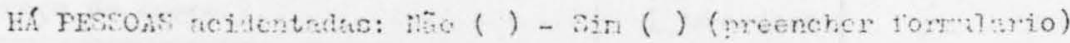

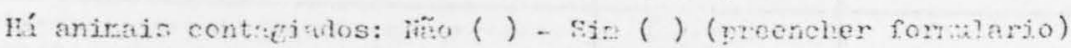

\section{IIACINOSTJCO}

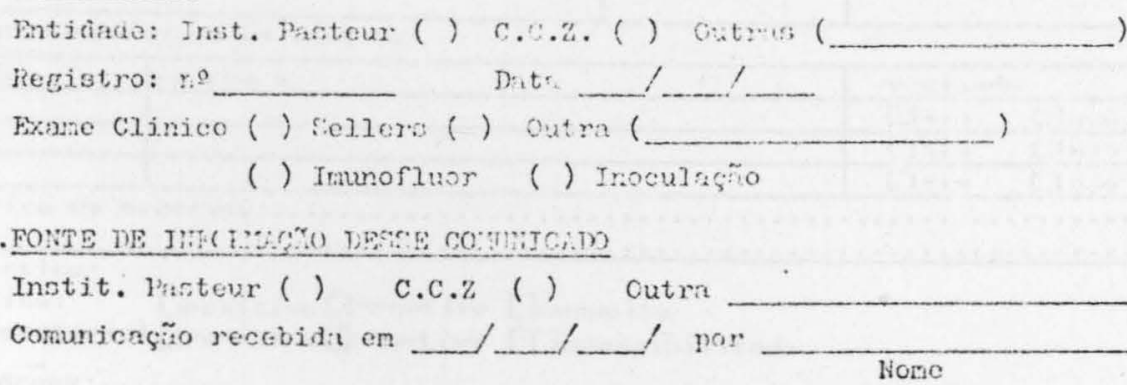

OBS: É inportante indicar usa rus, jærcja, e:seola, etc... do none conhe cido, tola vez que o lokil ( rua) nĩo tiver noze próprio e ou nu meraçño rezular: 


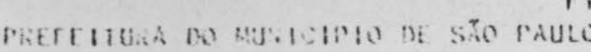

ficha s: $5 \ldots \ldots \ldots$

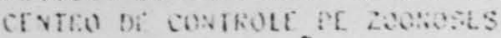

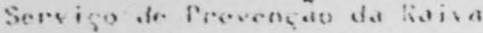

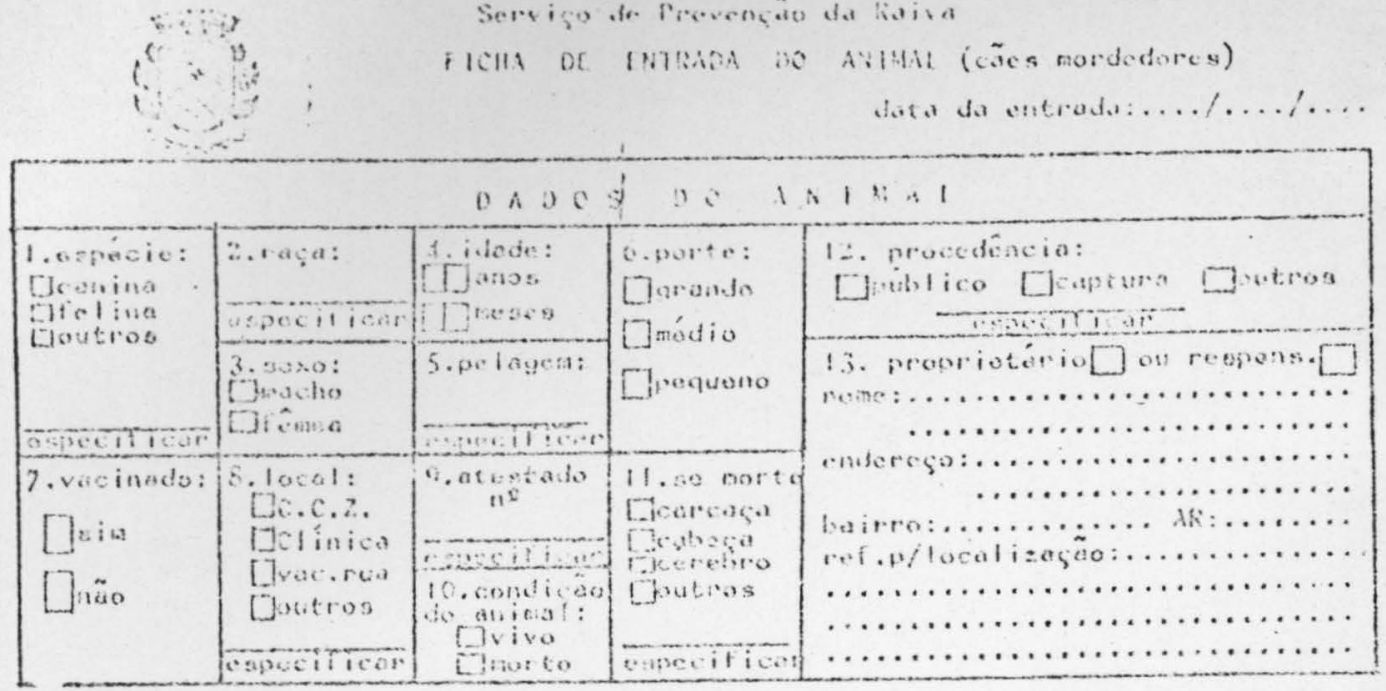

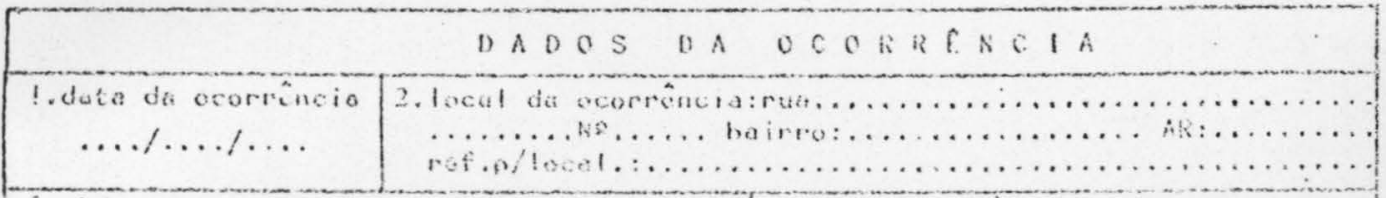

\begin{tabular}{|c|c|c|}
\hline 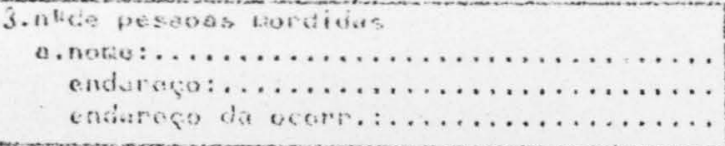 & 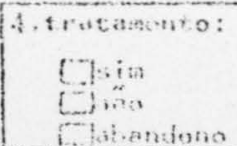 & Shlocel do crotemento \\
\hline 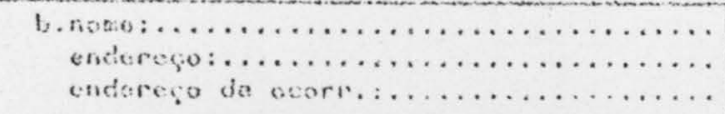 & 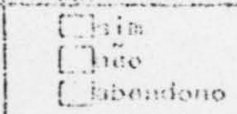 & \\
\hline 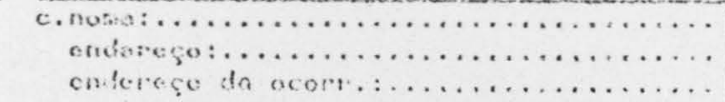 & Cination & \\
\hline
\end{tabular}

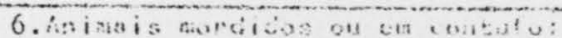

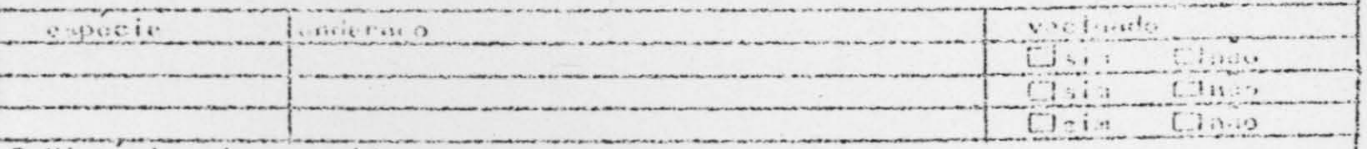

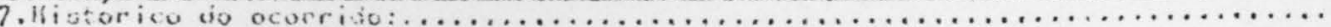

E. Diaturatico:

o.clínico: Lipositivo Dangativo Demspeito

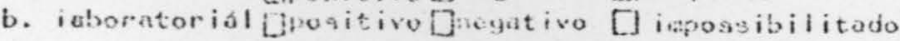

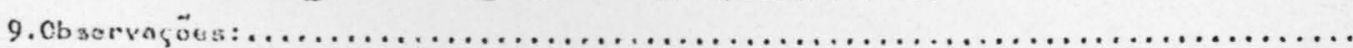

.

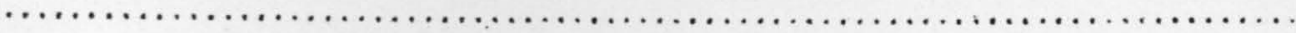

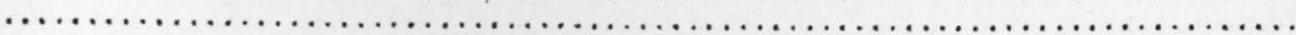

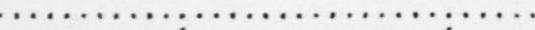

Asz. do Hét, - Vet. Fessunsáve 